Article

\title{
Optimized Design of a Swirler for a Combustion Chamber of Non-Premixed Flame Using Genetic Algorithms
}

\author{
Daniel Alejandro Zavaleta-Luna ${ }^{1}$, Marco Osvaldo Vigueras-Zúñiga ${ }^{1,2}$ (D), \\ Agustín L. Herrera-May ${ }^{1,3}(\mathbb{D})$, Sergio Aurelio Zamora-Castro ${ }^{1}(\mathbb{D})$ and \\ María Elena Tejeda-del-Cueto $1,2, *$ (D) \\ 1 Master in Applied Engineering, Veracruzana University, 94294 Veracruz, Mexico; \\ zs17024372@estudiantes.uv.mx (D.A.Z.-L.); mvigueras@uv.mx (M.O.V.-Z.); leherrera@uv.mx (A.L.H.-M.); \\ szamora@uv.mx (S.A.Z.-C.) \\ 2 Mechanical Engineering Department, Veracruzana University, 94294 Veracruz, Mexico \\ 3 Micro and Nanotechnology Research Center, Veracruzana University, 94294 Veracruz, Mexico \\ * Correspondence: etejeda@uv.mx
}

Received: 13 March 2020; Accepted: 26 April 2020; Published: 3 May 2020

check for updates

\begin{abstract}
Recirculation in a combustion chamber is required for stabilizing the flame and reducing pollutants. The swirlers can generate recirculation in a combustion chamber, inducing a swirling flow that breaks vorticity and improves the mixing of air and fuel. The swirl number $\left(S_{n}\right)$ is related to the formation of recirculation in conditions of high-intensity flows with $S_{n}>0.6$. Thus, the optimized design of a swirler is necessary to generate enough turbulence that keeps the flame stable. We present the optimized design of a swirler considering the main parameters for a non-premixed combustion chamber. This optimization is made with genetic algorithms to ensure the generation of a recirculation zone in the combustion chamber. This recirculation phenomenon is simulated using computational fluid dynamics (CFD) models and applying the renormalization group (RNG) $k-\varepsilon$ turbulence method. The chemistry is parameterized as a function of the mixture fraction and dissipation rate. A CFD comparison of a baseline swirler model and the proposed optimized swirler model shows that a recirculation zone with high intensity and longer length is generated in the primary zone of the combustion chamber when the optimized model is used. Furthermore, the CFD models depict swirling effects in the turbulent non-premixed flame, in which the stabilization is sensitive to the recirculation zone. The temperature results obtained with the CFD models agree well with the experimental results. The proposed design can help designers enhance the performance of combustion chambers and decrease the generation of $\mathrm{CO}$ and $\mathrm{NO}_{\mathrm{x}}$.
\end{abstract}

Keywords: swirler; optimized; genetic algorithms; recirculation; combustion; CFD; experimental validation

\section{Introduction}

Recirculation has an important role in most combustion systems. Several equipments such as combustion chambers, gas turbines, and industrial furnaces need recirculation to increase the combustion efficiency and keep the flame stable [1-3]. Recirculation is generated by a reversible toroidal flow that causes a low-pressure zone and a break in the vorticity [4]. This allows efficient mixing between hot gaseous fuel and fresh air entering the combustor [5,6]. Lefebvre and Ballal [7] showed that the process of mixing and combustion occurs inside the primary zone. This primary zone provides an anchor to flame and supplies the temperature, time, and turbulence necessary to achieve complete combustion [8]. The formation of a recirculation zone depends on the swirl number, which is an important parameter in swirling flows [9]. It allows the generation of toroidal recirculation zone to 
burn the fuel and prevent the formation of nitrogen oxide $\left(\mathrm{NO}_{\mathrm{x}}\right)$. Mundus and Kwark [10,11] reported that the emissions generated during the combustion can be reduced keeping a flow with rotation and controlling the flame intensity. The flame instability can increase the $\mathrm{CO}$ and $\mathrm{NO}_{\mathrm{x}}$ emissions; therefore, swirl flows with a sufficient amount of turbulence are required to induce a reversal flow and define a recirculation zone [12-17]. Tuttle [18] described the importance of mechanical components to generate a recirculation zone inside a combustion chamber. Tejeda-del-Cueto [19] indicated that flame stability could be achieved through three means: the generation of turbulence using a bluff body, swirling the flow or a combination with a bluff body to improve mixing of the reactants, and finally the optimization of air injection. Furthermore, Kilik [20] studied high-intensity turbulence in the primary zone using perforated plates with spiral-shaped strips inside a tube or by swirler, which was the most efficient method to inject tangential flows.

A swirler has a set of directed vanes to generate a centrifugal force in the flow, which moves the fluid with a swirling shape within the walls of the flame tube (liner). Valera-Medina [21] observed that flow with high turbulence can produce constant temperature during combustion, avoiding the formation of hot spots. The vane angle of a swirler influences the flame behavior and the pollutant emissions [21-23]. For the swirler design, it is necessary to develop analytical and numerical methods to optimize their performance. Several experimental studies have determined the rotatory flows generated by swirlers and their effect on combustion [24-28]. In addition, computational fluid dynamics (CFD) models have been used to predict the flow behavior in function of the swirler geometry [29-34]. The swirler designs are based on preliminary combustion chamber models [11,29,35,36]. Swirler geometry is defined by variables such as the swirl number, pressure drop due to mass flow, and the area of the swirler. These variables influence the formation of a recirculation zone at the primary area inside the combustion chamber as well as flame stability [35].

Genetic algorithm (GA) is a method that is used to solve constrained and unconstrained optimization problems considering natural selection and genetics [37]. Hiroyasu [38] used genetic algorithms to improve fuel efficiency and reduce the generation of pollutants during the combustion of a diesel engine. By using this method, the operating costs and $\mathrm{NO}_{\mathrm{x}}$ generation were reduced. On the other hand, Seneca et al. [39] and Liu et al. [40] used genetic algorithms to determine the optimal geometry of a combustion chamber, reducing the fuel consumption and pollutant emissions. They observed that $\mathrm{NO}_{x}$ generation and fuel consumption are reduced by varying the parameters of fuel injection and the geometry of the combustion chamber. In order to improve the performance of a combustion chamber, we propone the optimal design of a swirler using genetic algorithms. This design considers the main parameters of a swirler and the physical limitations of the combustor, as well as the conditions to enhance the recirculation in the combustion chamber. In addition, CFD models are developed to study the recirculation zone generated by the swirler and the temperature behavior of the flame under real operating conditions. The results of the CFD simulations show suitable conditions for a complete combustion. Furthermore, the optimized swirler generates high-intensity turbulence that can decrease the formation of $\mathrm{CO}$ and $\mathrm{NO}_{\mathrm{x}}$. The response of the temperature behavior obtained using CFD models agrees well with the experimental results.

\section{Design}

A swirler induces a flow with rotation to generate axisymmetric stagnation in the center of the flame tube, improving the flame stability [41]. Nowadays, there are two types of swirlers [42]: annular and axial. In this work, we present the optimized design of an axial swirler. Figure 1 depicts a schematic view of an axial swirler, in which the flow is axially applied. 


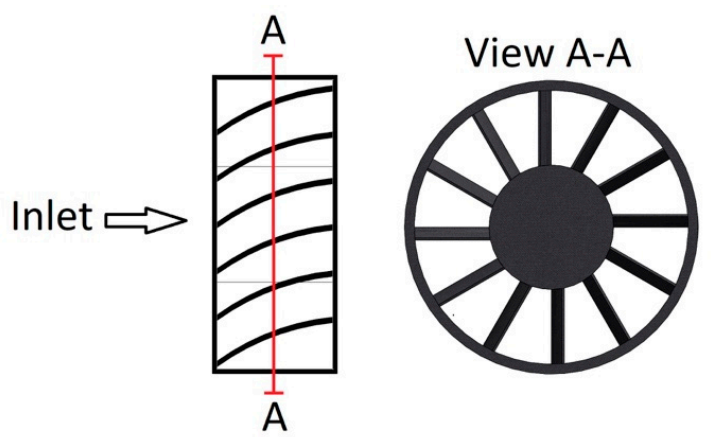

Figure 1. Schematic view of an axial swirler.

The vanes of an axial swirler have an outlet angle used to direct the air flow. This swirler generates a low-pressure drop, since vanes do not have a sharp change of direction. Keshtkar [43] demonstrated that the variation of vane angle can affect the size of the flame and decrease the pollutants generated during combustion. These swirler vanes can be designed with two shape types: flat or curved [44]. Thus, Beer and Syred [45] evaluated the performance of curved and flat vanes of swirlers. They reported that curved vanes achieve higher efficiency (about 70\%) and generate less pressure drop compared with flat vanes. Lefebvre and Ballal [7] described a conventional notation for elements of an axial swirler, as shown in Figure 2.

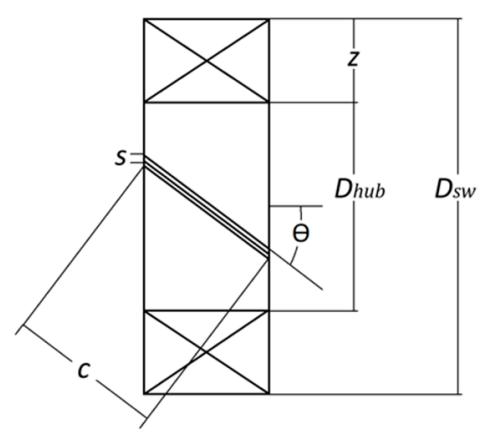

Figure 2. Geometrical parameters of the main elements of an axial swirler. Where $D_{s w}$ is the swirler diameter, $\theta$ is the vane angle, $D_{h u b}$ is the swirler hub diameter, $c$ is the vane chord, $s$ is the vane space, and $z$ is the annular space length formed by the hub diameter and the swirler diameter.

\section{Design of Swirler}

The design procedure presented in this work follows steps as shown in Figure 3. The operating conditions and physical dimensions of the combustion chamber defined the starting point for optimization. Deep research was done to determine the variables, objective (fitness) function, limits, and restrictions for running the genetic algorithm. The design procedure finished when the swirl number is maximized, keeping variables within the established limits. 


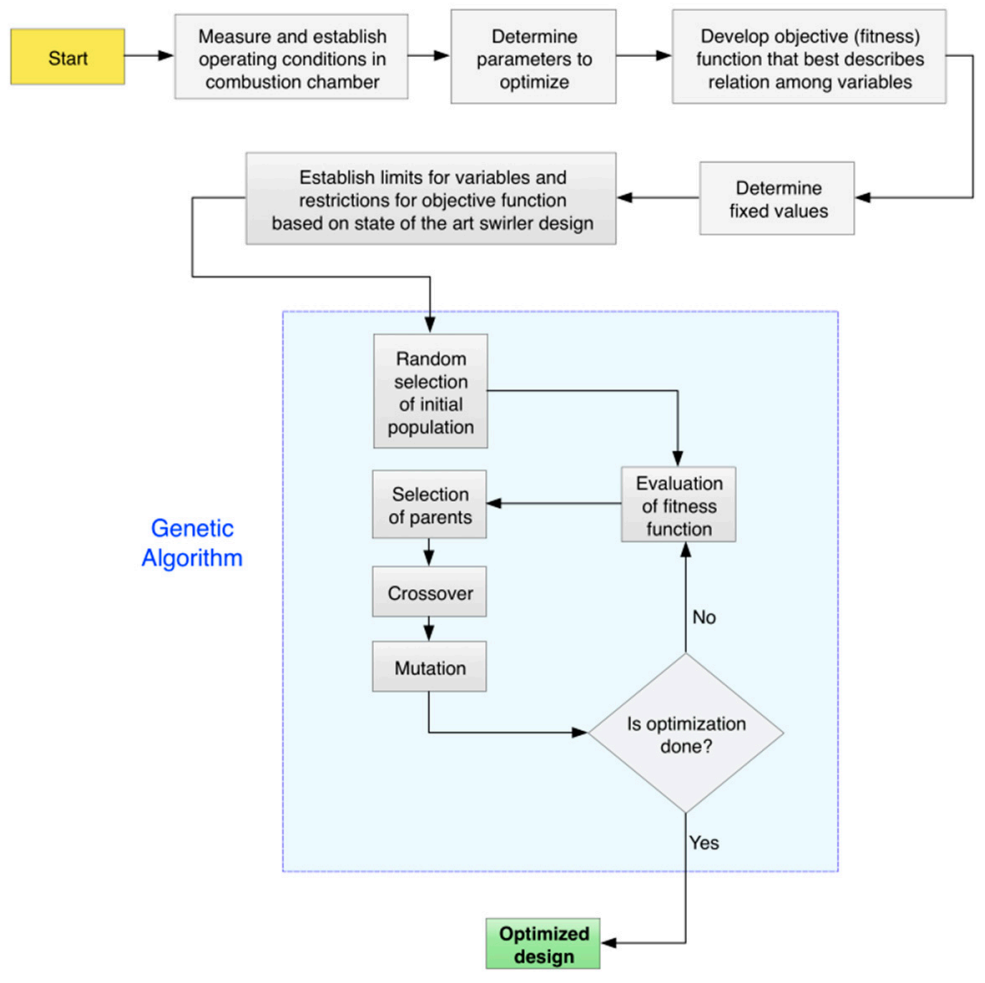

Figure 3. Flow chart of design procedure.

Generally, the design of swirlers is based on three variables: swirl number, mass flow, and swirler area [7].

\subsection{Swirl Number}

The swirl number $\left(S_{n}\right)$ is the main variable considered in swirler design. The swirl number is the ratio of the axial flux of angular momentum $\left(G_{t}\right)$ to the axial flux of the axial momentum $\left(G_{x}\right)$. The swirl number can be determined by [43]:

$$
S_{n}=\frac{G_{t}}{G_{x} r_{a}}
$$

where $r_{a}$ is the hydraulic radius.

Beer and Syred [45] proposed the following equation to determine the swirl number $\left(S_{n}\right)$ in an annular swirler with a constant vane angle:

$$
S_{n}=\frac{2}{3}\left(\frac{1-\left(\frac{D_{h u b}}{D_{s w}}\right)^{3}}{1-\left(\frac{D_{h u b}}{D_{s w}}\right)^{2}}\right) \tan (\theta) .
$$

\subsection{Mass Flow}

Knight and Walker [46] reported that the mass flow $\left(\dot{m}_{s w}\right)$ of air entering the combustion chamber is a requirement in the swirler design. The $\dot{m}_{s w}$ can be expressed as:

$$
\dot{m}_{s w}=\left\{\frac{2 \rho \Delta P_{c o m b}}{k_{s w}\left[\frac{\sec (\theta)}{A_{s w}}\right]^{2}-\frac{1}{A_{L}^{2}}}\right\}^{\frac{1}{2}}
$$


where $A_{s w}$ is the swirler frontal area, $A_{L}$ is the liner area, $\Delta P_{\text {comb }}$ is the pressure drop through combustor, $k_{s w}$ is the vane shape factor, and $\rho$ is the air density.

The pressure drop $\left(\Delta P_{s w}\right)$ in the combustor due to the mass flow in a swirler must be minimal.

\subsection{Swirler Area}

The frontal area $\left(A_{s w}\right)$ of the swirler represents the relationship between the frontal annular area and the area occupied by the vane profiles. This parameter can be calculated by [47]:

$$
A_{s w}=\frac{\pi}{4}\left(D_{s w}^{2}-D_{h u b}^{2}\right)-\frac{n_{v} t_{v}}{2}\left(D_{s w}-D_{h u b}\right)
$$

where $n_{v}$ is the number of swirler vanes and $t_{v}$ is the thickness of the swirler vane.

\section{Genetic Algorithm}

The genetic algorithm (GA) of MATLAB (R2015b, The MathWorks, Inc., Natick, USA) is a tool that enables defining the value of the parameters involved in an optimization process. These parameters are restricted by limits that allow the values to be optimized efficiently [37]. The genetic algorithm used in this work is based on generating a set of individuals called a population of possible solutions; these individuals are manipulated through the intervention of the following operators: selection, crossover, and mutation to generate a new generation of individuals. When the new generation is created, the new individuals are analyzed, and their properties are evaluated to determine if convergence criteria are satisfied or not. If the convergence criteria are satisfactory, the process stops, but if the convergence criteria are not satisfactory, the process continues until a convergence solution is found [48,49].

\subsection{Objective Function}

In the design of swirlers, we consider three main parameters: the swirl number, the mass flow, and the swirler area. We propone the swirl number as objective function, which will be maximized to achieve a stability in the flame. This is due to the generation of a recirculation zone in the combustion chamber. The objective function of swirl number $\left(S_{n}\right)$ can be represented by:

$$
S_{n}=\frac{2}{3} \frac{\left(D_{s w}^{2}+D_{s w} D_{h u b}+D_{h u b}^{2}\right)(\tan \theta)}{\left.\left[\frac{4 D_{s w}}{\pi\left(D_{s w}-D_{h u b}\right)}\right)\left(\sqrt{\frac{\sec ^{2} \theta}{\left(\frac{2 \rho \Delta P_{c o m b}}{k_{s w} \dot{m}_{s w}^{2}}\right)}}+\left(\frac{2 n_{v} t_{v} D_{s w}}{\pi}\right)\right)\right]}
$$

where $\Delta P_{s w}$ is the swirler pressure drop, $n_{v}$ is the number of vanes, $\dot{m}_{s w}$ is the mass air flow, and $t_{v}$ is the thickness.

\subsection{Limits}

Table 1 shows the values of $k_{s w}, n_{v}, t_{v}$, and $\theta$ recommended by [46,50] for swirler design. These values can allow the generation of a recirculation zone in the combustion chamber. However, Keshtkar [43] and Beer and Syred [45] reported that a similar behavior of the recirculation zone is generated starting with a vane angle of $10^{\circ}$. Based on these research studies, the minimum angle value is modified. In addition, the shape of the curved vane is considered. Table 2 depicts the range of values of the main geometrical parameters used by the genetic algorithm in the swirler design. 
Table 1. Recommended values of geometrical parameters for the swirler design.

\begin{tabular}{ccc}
\hline Geometrical Parameter & Minimum & Maximum \\
\hline$\theta$ & $30^{\circ}$ & $60^{\circ}$ \\
$t_{v}$ & $0.7 \mathrm{~mm}$ & $1.5 \mathrm{~mm}$ \\
$n_{v}$ & 8 & 16 \\
$k_{s w}$ & 1.15 (curved vane) & 1.3 (flat vane) \\
\hline
\end{tabular}

Table 2. Limits of the geometrical parameters used in the genetic algorithms for the swirler design.

\begin{tabular}{ccc}
\hline Variable & Minimum & Maximum \\
\hline$\theta$ & $10^{\circ}$ & $60^{\circ}$ \\
$t_{v}$ & $0.7 \mathrm{~mm}$ & $1.5 \mathrm{~mm}$ \\
$n_{v}$ & 8 & 16 \\
\hline
\end{tabular}

\subsection{Restriction Parameters}

The swirl number directly influences the formation of the recirculation zone in the combustion chamber. However, it is necessary for a higher turbulence intensity of the flow. For this, the swirl number must increase to generate a backward flow. Beer and Syred [45] indicated that flows with high-intensity turbulence have a range of swirl numbers between 0.6 and 2.5. Thus, the recirculation zone increases, which establishes the main restriction of the objective function in the genetic algorithms.

Another parameter is the ratio of the hub diameter $\left(D_{h u b}\right)$ to the swirler diameter $\left(D_{s w}\right)$. This ratio allows the reduction of the pressure drop in the flow, which is established by the ratio $D_{\text {hub }} / D_{\text {sw }}$. This ratio has a recommended value to reduce losses of $D_{\mathrm{hub}} / D_{\mathrm{sw}}=0.5$. Nevertheless, Beer and Syred [45] expressed that recirculation zones with similar behavior can be generated when the ratio $D_{\text {hub }} / D_{\mathrm{sw}}$ has values from 0.4 to 0.6 . Based on this restriction and considering $D_{s w}=9.8 \mathrm{~cm}, D_{h u b}$ is measured from the ratios $D_{\text {hub }} / D_{\mathrm{sw}}=0.4$ and $D_{\mathrm{hub}} / D_{\mathrm{sw}}=0.6$. Thus, the maximum and minimum dimensions of $D_{\text {hub }}$ are $5.88 \mathrm{~cm}$ and $3.92 \mathrm{~cm}$, respectively. Another restriction is added regarding the need to insert the fuel injector at the center of the swirler. It is established that the minimum value of $D_{h u b}$ is $5 \mathrm{~cm}$. Table 3 shows the values of the restriction parameters used in genetic algorithms.

Table 3. Range of restrictions for swirler design using genetic algorithms.

\begin{tabular}{ccc}
\hline Restrictions & Minimum & Maximum \\
\hline$S_{n}$ & 0.6 & 2.5 \\
$D_{\text {hub }} / D_{\mathrm{sw}}$ & 0.4 & 0.6 \\
$D_{\text {hub }}$ & $0.05 \mathrm{~m}$ & $0.0588 \mathrm{~m}$ \\
\hline
\end{tabular}

\subsection{Constant Values}

Figure 4 shows the different components of the combustion chamber design. In this design, the diffuser has a length of $5.6 \mathrm{~cm}$, an inlet diameter of $6 \mathrm{~cm}$, and an outlet diameter of $15.70 \mathrm{~cm}$. The flame tube has a cylindrical shape with an internal diameter and length of $10.70 \mathrm{~cm}$ and $26.10 \mathrm{~cm}$, respectively. It has 5 secondary holes with diameters of $0.54 \mathrm{~cm}$ around the flame tube, which are located $12 \mathrm{~cm}$ from the air inlet. Moreover, it has 5 tertiary holes with diameters of $1.20 \mathrm{~cm}$ that are located $18 \mathrm{~cm}$ from the air inlet. The fuel injector has a diameter of $1.30 \mathrm{~cm}$ and a length of $11.50 \mathrm{~cm}$. Combustion exhaust gases leave the chamber through a nozzle, which has a length of $5.60 \mathrm{~cm}$ and interior and outer diameters of $15.70 \mathrm{~cm}$ and $6.0 \mathrm{~cm}$, respectively. The combustion chamber has two peepholes of $2.54 \mathrm{~cm}$ diameter. The first and second peephole are located $20.60 \mathrm{~cm}$ and $26.60 \mathrm{~cm}$ from the air inlet, respectively. Table 4 shows the values of different parameters used in the objective function of the genetic algorithm. 


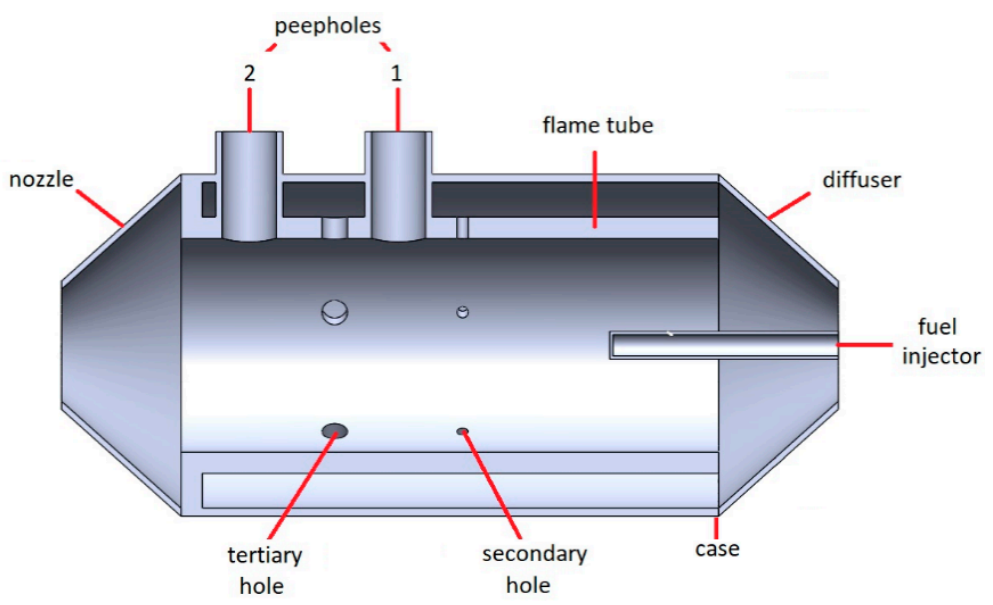

Figure 4. Diffuse flame combustion chamber.

Table 4. Values of different parameters considered in the objective function of the swirl number.

\begin{tabular}{cc}
\hline Parameters & Value \\
\hline Internal diameter of the case & $0.157 \mathrm{~m}$ \\
Diameter of combustor & $0.107 \mathrm{~m}$ \\
Minimum diameter of diffuser & $0.06 \mathrm{~m}$ \\
Air density & $1.16 \mathrm{~kg} / \mathrm{m}^{3}$ \\
Vane shape factor & 1.15 \\
Air mass flow & $4.398 \times 10^{-2} \mathrm{~kg} / \mathrm{s}$ \\
Percentage of air entering the combustor & $70 \%$ \\
Combustor pressure drop relative to dynamic pressure & $20 \mathrm{~Pa}$ \\
Ratio of the combustor pressure drop to the combustor inlet & 0.06 \\
Gas constant & $286.9 \mathrm{~N} \mathrm{~m} / \mathrm{kg}$ \\
Temperature of incoming air & $303.15 \mathrm{~K}$ \\
\hline
\end{tabular}

\subsection{Optimal Values}

The swirler depth is determined in proportion to $D_{s w}$, considering $40 \%$ of the swirler diameter. Table 5 shows the values obtained by the genetic algorithm. In addition, Figure 5 depicts the final design of the optimized swirler with the coupled injector.

Table 5. Values of optimum swirler design obtained by genetic algorithm.

\begin{tabular}{ccccc}
\hline $\boldsymbol{\theta}$ & $\boldsymbol{n}_{\boldsymbol{v}}$ & $\boldsymbol{t}_{\boldsymbol{v}}$ & $\boldsymbol{D}_{\text {hub }}$ & Depth \\
\hline $18^{\circ}$ & 8 & $0.001 \mathrm{~m}$ & $0.0576 \mathrm{~m}$ & $0.039 \mathrm{~m}$ \\
\hline
\end{tabular}

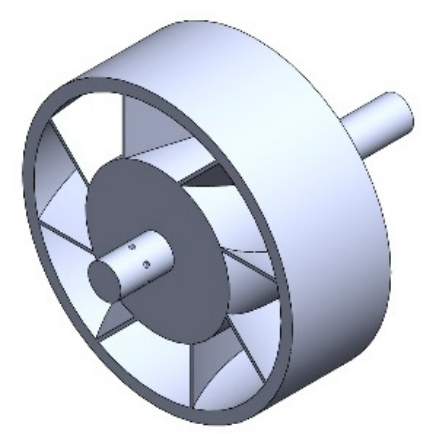

Figure 5. Optimized design of swirler with injector. 
The solidity is a parameter that intervenes in swirler design and is defined as the ratio of vane chord length to vane pitch. Martin [51] described that for an axial swirler, the solidity as a function of the vane angle is defined by the following equation:

$$
\sigma=\frac{c \sin \theta}{s}
$$

where $\sigma$ is the solidity of the vane, $c$ is the chord, $\theta$ is the vane angle, and $s$ is the gap between adjacent vanes.

Considering this, the solidity of the vanes of the designed swirler has a value of 0.51 , which indicates that the flow area increases, reducing the pressure drop of the element. In addition to this, since it is a value less than 1 , the generation of a high-intensity swirl number is favored.

\section{Numerical Models}

\subsection{CFD Model}

\subsubsection{Turbulence Model}

The RNG $k-\varepsilon$ turbulence model is a variation of the standard $k-\varepsilon$ turbulence model derived by Yakhot and Orszag, and it is based on the infinite scale expansion in $\eta$ [52]. This replaces the constant $C_{\varepsilon 1}$ by the function $C_{\varepsilon 1 R N G}$ within the transport equation for turbulence dissipation and is based on the theory of renormalization of groups through the solution of transport equations for the generation and dissipation of turbulence [53]. The turbulence model used for the analysis of recirculation zone and the flame behavior generated by proposed the swirler have been used in several research studies related to rotational flows, providing correct results in the turbulence developed in flows with high rotation and also good results in predicting the behavior of the steady-state combustion [54-58]. This RNG $k-\varepsilon$ turbulence model can be represented as:

$$
\begin{gathered}
\frac{\partial(\rho k)}{\partial t}+\frac{\partial\left(\rho u_{j} k\right)}{\partial x_{j}}=\frac{\partial}{\partial x_{j}}\left[\left(\mu+\frac{\mu_{t}}{\sigma_{k}}\right) \frac{\partial k}{\partial x_{j}}\right]+\mu_{t}\left(\frac{\partial u_{i}}{\partial x_{j}}+\frac{\partial u_{j}}{\partial x_{i}}\right) \frac{\partial u_{i}}{\partial x_{j}}-\rho \varepsilon \\
\frac{\partial(\rho \varepsilon)}{\partial t}+\frac{\partial\left(\rho u_{j} \varepsilon\right)}{\partial x_{j}}=\frac{\partial}{\partial x_{j}}\left[\left(\mu+\frac{\mu_{t}}{\sigma_{\varepsilon}}\right) \frac{\partial \varepsilon}{\partial x_{j}}\right]+C_{\varepsilon 1}^{*} \mu_{t} \frac{\varepsilon}{k}\left(\frac{\partial u_{i}}{\partial x_{j}}+\frac{\partial u_{j}}{\partial x_{i}}\right) \frac{\partial u_{i}}{\partial x_{j}}-C_{\varepsilon 2} \rho \frac{\varepsilon^{2}}{k}
\end{gathered}
$$

with

$$
\begin{gathered}
\mu_{t}=\rho C_{\mu} \frac{k^{2}}{\varepsilon} \\
C_{\varepsilon 1 R N G}=1.42-\frac{\eta\left(1-\frac{\eta}{\eta_{0}}\right)}{\left(1+\beta \eta^{3}\right)} \\
\eta=\sqrt{\mu_{t}\left(\frac{\partial u_{i}}{\partial x_{j}}+\frac{\partial u_{j}}{\partial x_{i}}\right)\left(\frac{\partial u_{i}}{\partial x_{j}} / \rho C_{\mu} \varepsilon\right)}
\end{gathered}
$$

where the term $\mu_{t}$ represents the turbulent viscosity and the value of the constants are $C_{\mu}=0.085$, $C_{\varepsilon 2}=1.68, \sigma_{\varepsilon}=1.3, \sigma_{k}=1.0, \beta=0.015$, and $\eta_{0}=4.38$.

\subsubsection{Laminar Flamelet Model}

The laminar flamelet model is based on the temperature and species mass fractions transport equations. These equations are standardized in terms of two variables: scalar dissipation $(\chi)$ and mixture fraction $(Z)[59,60]$, and they can be represented by:

$$
\rho \frac{\partial Y_{i}}{\partial t}=\rho \frac{\chi}{2} \frac{\partial^{2} Y_{i}}{\partial Z^{2}}+w_{i}-\rho\left(\frac{D \chi}{2}\right)^{1 / 2} k \frac{\partial Y_{i}}{\partial Z}
$$




$$
\rho \frac{\partial T}{\partial t}=\rho \frac{\chi}{2} \frac{\partial^{2} T}{\partial Z^{2}}+w_{T}-\rho\left(\frac{D \chi}{2}\right)^{1 / 2} k \frac{\partial Y}{\partial Z}
$$

where $w_{T}$ and $w_{i}$ are the chemical sources for temperature and species, $Y_{i}$ is the mass fraction of the specie $i, T$ is the temperature, $k$ is the curvature of a mixture fraction iso-line, and $t$ represents the time.

The laminar flamelet model uses the mixture fraction $(Z)$ to incorporate chemical reactions into the flame during turbulent combustion [61]. To quantify the proximity to balance, this model employs scalar dissipation $(\chi)$, which represents the stretching of the flame [60]. These parameters are expressed by:

$$
\begin{gathered}
\chi=2 D|\nabla Z|^{2} \\
\rho \frac{\partial Z}{\partial t}+\rho v_{k} \frac{\partial Z}{\partial \chi}=\frac{\partial}{\partial \chi}\left(\rho D \frac{\partial Z}{\partial \chi}\right)
\end{gathered}
$$

where $D$ is the diffusion coefficient and $v_{k}$ is the velocity.

Combustion is studied using the laminar flamelet model with a chemical kinetics mechanism [62], which incorporates 58 pollutants (including $\mathrm{CO}$ and $\mathrm{CO}_{2}$ ) and 270 reactions, but the chemical kinetics mechanism for NOx production is not included in this model.

\subsubsection{Numerical Modeling}

\section{Meshing and Boundary Conditions}

A CFD model of the combustion chamber is developed to study its performance using the finite volume method in Fluent ANSYS. Combustion is modeled using liquefied petroleum gas (LPG) as fuel, which is a mixture of $80 \%$ propane and $20 \%$ butane on a volumetric basis. This concentration can decrease the contaminant emissions [63]. Figure 6 shows the longitudinal section of the combustion chamber mesh.

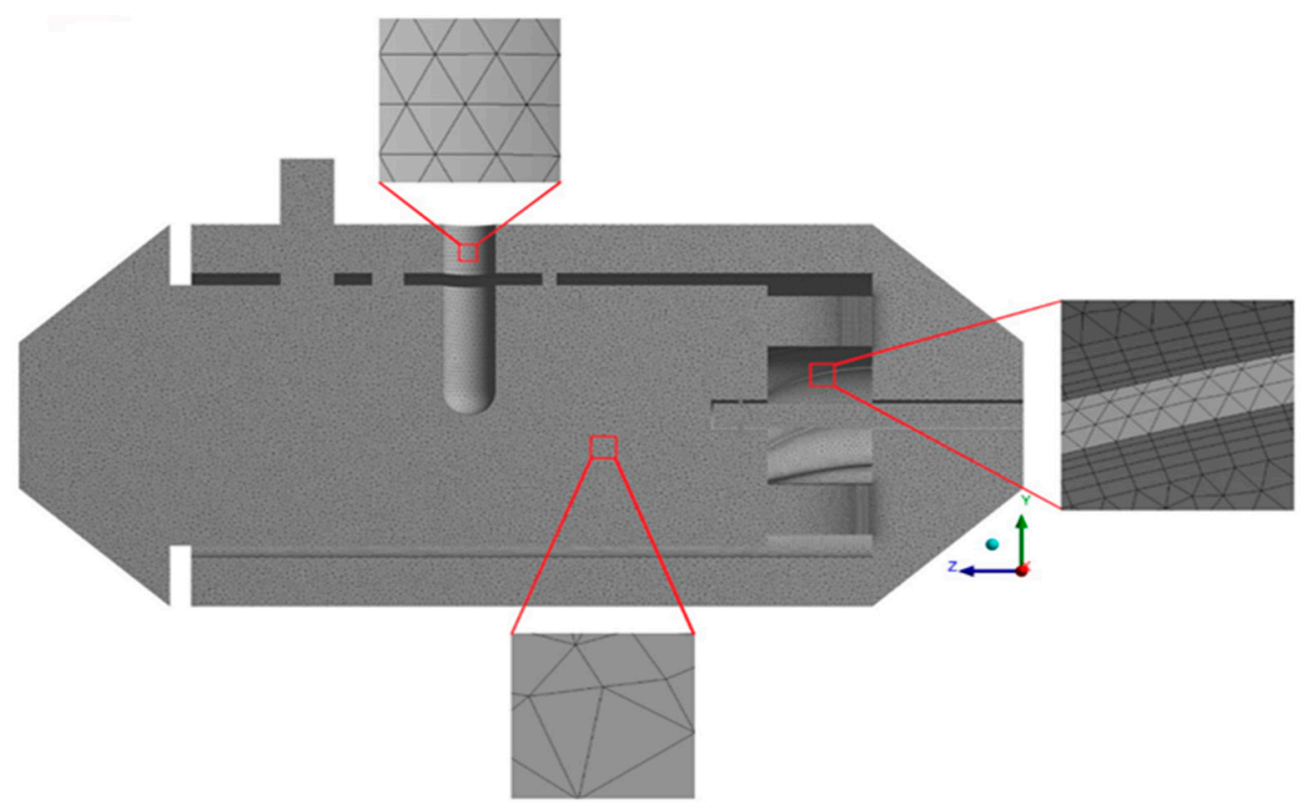

Figure 6. Mesh used in the computational fluid dynamics (CFD) model of the combustion chamber, including a view of the boundary layer on the swirler vanes (right), the boundary of the thermocouple (top), and the elements of the burner (bottom).

The mesh used represents the entire volume of the combustion chamber, and it is set to simulate the fluid that constitutes the flow along the combustor. The mesh is of the tetrahedral type and the use of a boundary layer is established in the swirler vanes, with local refinement on the internal 
and external surfaces of the vanes. The mesh has 7,555,837 elements and 1,565,195 nodes with an approximate quality of $84 \%$. The residual values of continuity, momentum, turbulent kinetic energy, mixture fraction, and variance of mixture fraction were 10-4, while for energy, it was 10-7.

Table 6 indicates the boundary conditions used in the CFD model of the combustion chamber.

Table 6. Boundary conditions for numerical analysis.

\begin{tabular}{cc}
\hline Variable & Value \\
\hline Air inlet pressure & $2100(\mathrm{~Pa})$ \\
Mass air flow & $4.398 \times 10^{-2}(\mathrm{~kg} / \mathrm{s})$ \\
Air temperature & $303.15(\mathrm{~K})$ \\
Fuel inlet pressure & $2100(\mathrm{~Pa})$ \\
Mass fuel flow & $2.95 \times 10^{-4}(\mathrm{~kg} / \mathrm{s})$ \\
Fuel temperature & $300.15(\mathrm{~K})$ \\
Combustion chamber outlet pressure & $375(\mathrm{~kg} / \mathrm{s})$ \\
Wall temperature & $300(\mathrm{~K})$ \\
\hline
\end{tabular}

Given that the model is based on density terms, the second-order upwind discretization scheme is used. This scheme provides a higher-order precision at the cell faces using Taylor series expansion of the cell-centered solution at its centroid [64,65].

\section{Cold Air Flow}

The recirculation zone generated by the optimized swirler was compared to a baseline swirler under the same boundary conditions. Figure 7 shows the views of the optimized swirler and the baseline swirler. Figure 7a,b shows isometric and front views of the baseline swirler, while Figure 7c,d depicts the isometric and front views of the optimized swirler.

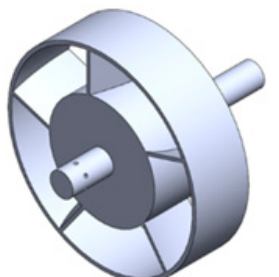

a)

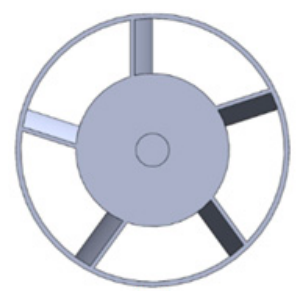

b)

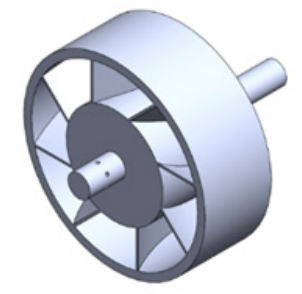

c)

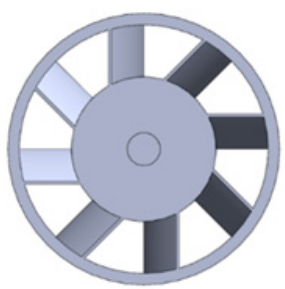

d)

Figure 7. Swirlers compared in numerical analysis. (a) baseline swirler, (b) front view of the baseline swirler, (c) proposed optimized swirler, (d) front view of the proposed optimized swirler.

Table 7 shows the comparison of the design parameters for both an optimized swirler and baseline swirler. 
Table 7. Comparative table of the design parameters of the swirlers.

\begin{tabular}{ccccccc}
\hline & $\boldsymbol{\theta}$ & $\boldsymbol{n}_{\boldsymbol{v}}$ & $\boldsymbol{t}_{\boldsymbol{v}}$ & $\boldsymbol{D}_{\boldsymbol{h u b}}$ & Depth & $\boldsymbol{S}_{\boldsymbol{n}}$ \\
\hline Optimized swirler model & $18^{\circ}$ & 8 & $0.001 \mathrm{~m}$ & $0.0576 \mathrm{~m}$ & $0.039 \mathrm{~m}$ & 2.48 \\
Baseline swirler model & $12^{\circ}$ & 5 & $0.0015 \mathrm{~m}$ & $0.06 \mathrm{~m}$ & $0.03 \mathrm{~m}$ & 0.18 \\
\hline
\end{tabular}

Figure 8 shows the behavior of the flow circulating in the combustion chamber. Figure $8 \mathrm{a}$ represents the velocity path lines generated by the optimized swirler. On the other hand, Figure $8 \mathrm{~b}$ shows the velocity path lines generated by the baseline swirler. It is observed that the recirculation zone generated by the optimized swirler has a longer length than the baseline swirler and the velocities developed reach up to $5 \mathrm{~m} / \mathrm{s}$; it is also observed that a high-intensity turbulence zone is developed at the primary zone. Additionally, a low-speed region is found at the combustion chamber core, ending close to the secondary zone. The recirculation zone obtained with the baseline swirler is wider and shorter than its optimized counterpart. The recirculation zone ends at the primary zone and is bounded by the hub of the swirler. Velocities developed with the baseline swirler are smaller, having average values of $3 \mathrm{~m} / \mathrm{s}$.

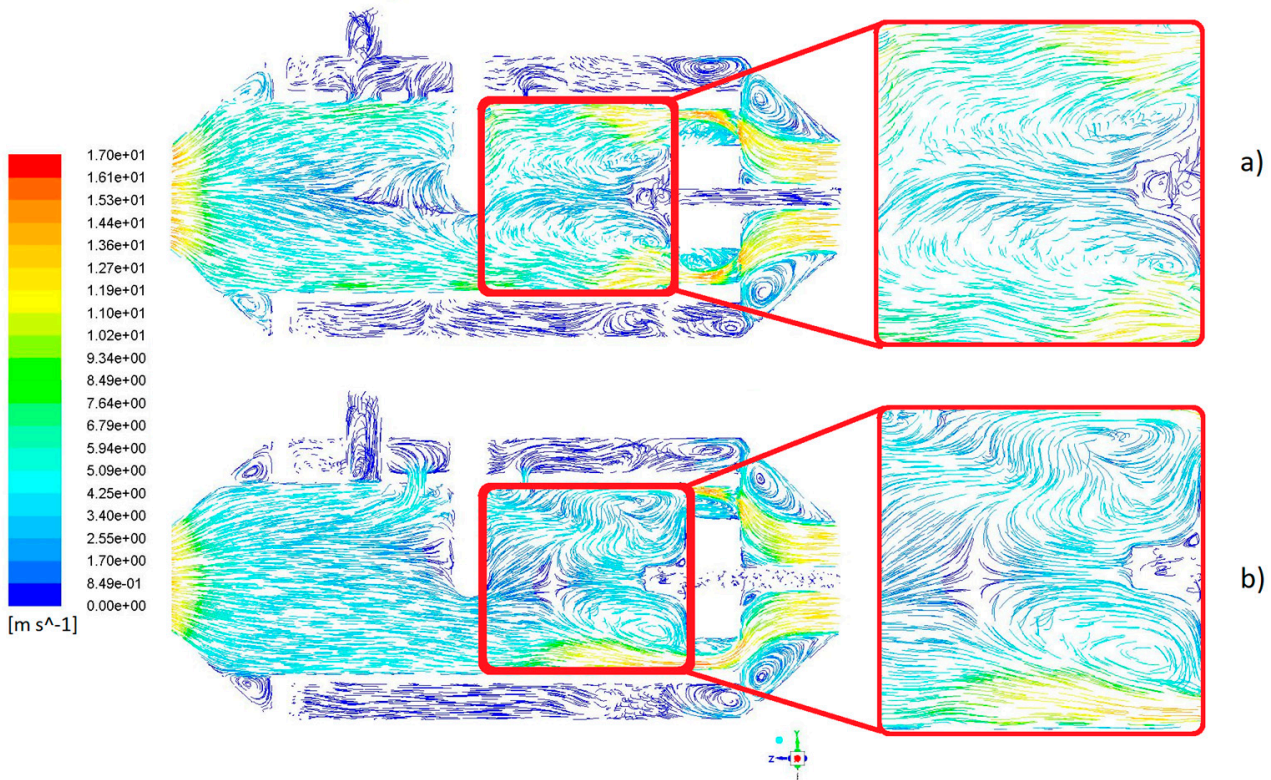

Figure 8. Path lines of velocity along the $y z$ plane of a CFD model of a combustion chamber. (a) Recirculation zone generated by the optimized swirler model, (b) recirculation zone generated by the baseline swirler model.

As the optimized swirler shows better behavior, further analysis is performed regarding cold air flow conditions. Figure 9 shows the air velocity streamlines in the $z x$ plane of the combustion chamber using the optimized swirler. Figure 9 a depicts a recirculation core formed by air inside the primary zone, which benefits the mixing process by retaining the particles in that zone and delays the process in order to burn properly. In addition, Figure $9 \mathrm{~b}$ illustrates the rotating flow along the combustor. 

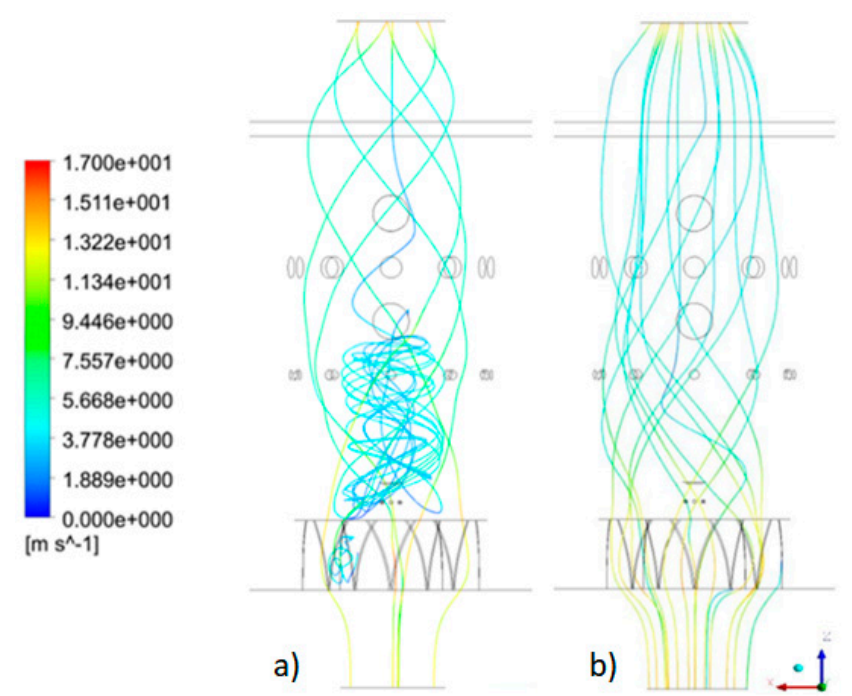

Figure 9. View of air velocity streamlines along $z x$ plane of a CFD model of a combustion chamber.

\section{Combustion}

Figure 10 shows several $x y$ planes along the combustion chamber used to show flow behavior during combustion conditions. The origin point is considered at the inlet of the combustion chamber, and each plane is located at the following distances: plane $1(10.50 \mathrm{~cm})$, plane $2(14 \mathrm{~cm})$, plane 3 $(17.60 \mathrm{~cm})$, plane $4(23.60 \mathrm{~cm})$, plane $5(26.60 \mathrm{~cm})$, and plane $6(30 \mathrm{~cm})$.

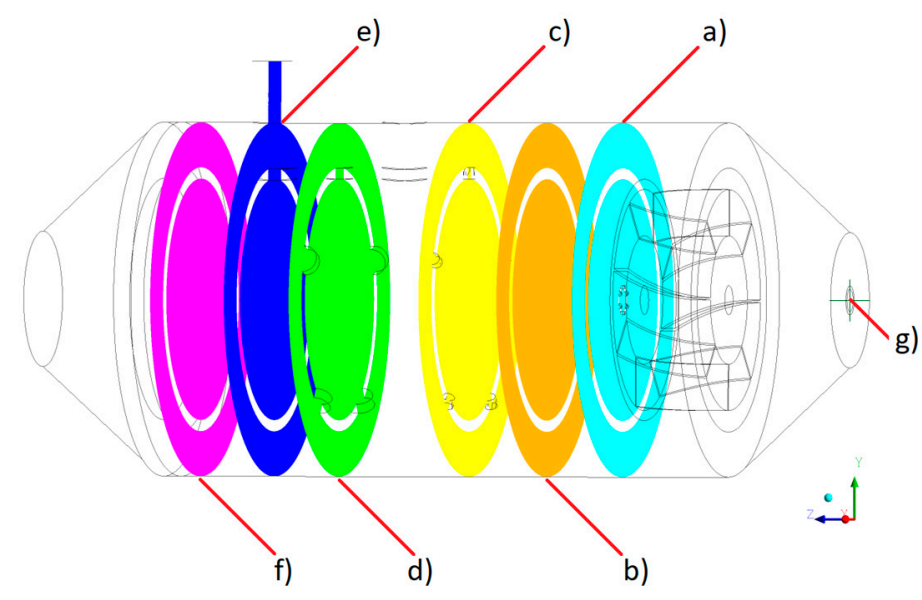

Figure 10. $x y$ planes and origin point of the combustion chamber. (a) plane 1, (b) plane 2, (c) plane 3, (d) plane 4, (e) plane 5, (f) plane 6, and (g) origin point.

Figure 11a,b depict the optimized and baseline swirler velocity vectors in plane 1 , respectively. Figure 11a shows that the slowest velocity zone is located at the center of the combustion chamber and has a hub-like shape. In this zone, average velocities of $3 \mathrm{~m} / \mathrm{s}$ are obtained, and it is surrounded by a uniform high-velocity zone, with maximum velocities of $14 \mathrm{~m} / \mathrm{s}$. On the other hand, in Figure $11 \mathrm{~b}$, it is observed that the zone of low velocity begins at the center of the combustor and has a star-like shape, which expands from the center of the hub to the radially middle section of the swirler vanes. This low-velocity zone is surrounded by a high-velocity zone, with an average value of $9 \mathrm{~m} / \mathrm{s}$. 


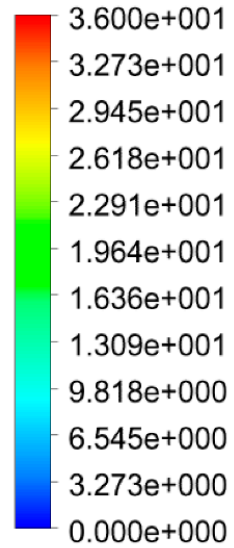

$\left[\mathrm{m} \mathrm{s}^{\wedge}-1\right]$

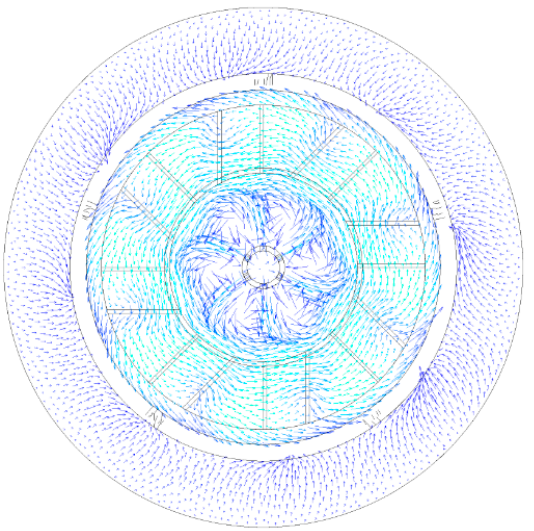

a)

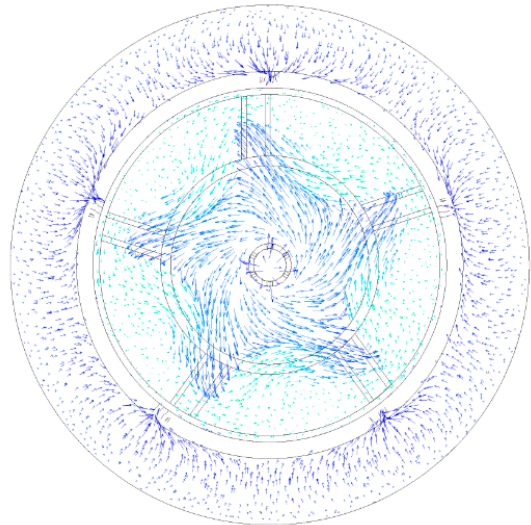

b)

Figure 11. Velocity vectors during combustion in plane 1 of the combustion chamber. (a) Optimized swirler, (b) baseline swirler.

Figure 12a,b represent the velocity vectors in plane 2 of the combustion chamber with the optimized and baseline swirler, respectively. Figure 12a shows that the size of the low-velocity zone decreased and remains at the center of the combustion chamber. It is also observed that the vectors surrounding the low-velocity zone maintain a constant speed of $8 \mathrm{~m} / \mathrm{s}$ and rotate inside the flame tube. On the other hand, in Figure 12b, it is observed that the velocity remains constant inside the flame tube with velocity magnitudes comparable to those of the optimized swirler; however, the direction of the vectors indicates that there is no a swirling pattern in the transverse plane to achieve a constant rotation. Most of the air flow passing through the combustion chamber is located in the annular area between the casing and the flame tube.

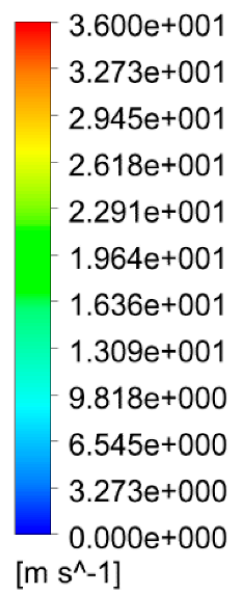

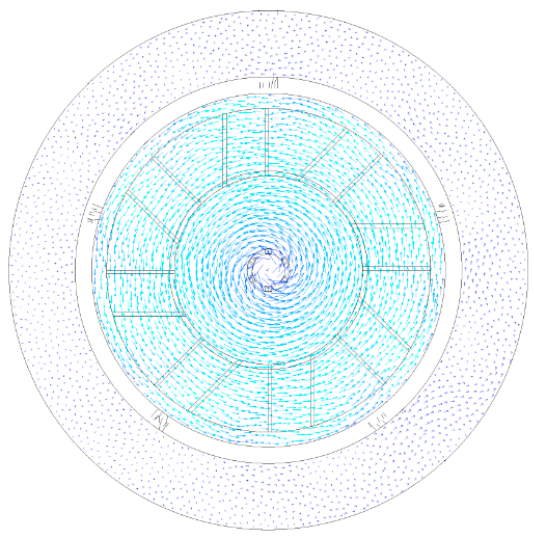

a)

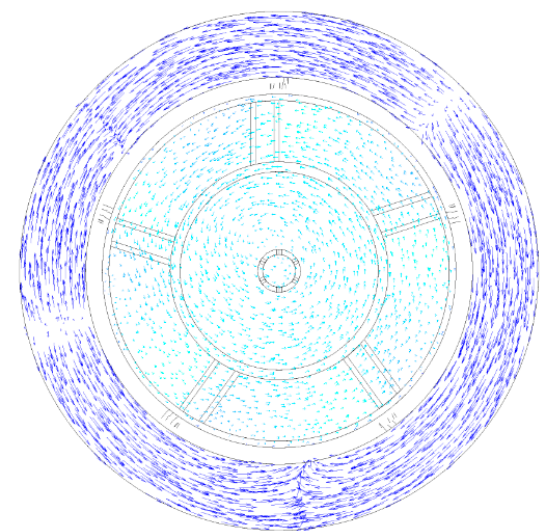

b)

Figure 12. Velocity vectors during combustion in plane 2 of the combustion chamber. (a) Optimized swirler, (b) baseline swirler.

Figure 13a,b represent the velocity vectors in plane 3 of the combustion chamber with the optimized and baseline swirler, respectively. It is observed that in Figure 13a, high velocities are kept constant near the liner walls while in the central zone, a low-velocity profile is found; however, the flow is maintained rotating throughout the transverse plane of the flame tube. In addition, it is observed that fresh air enters the flame tube through the secondary holes, which will benefit the burning of unburned fuel in the primary zone. On the other hand, Figure 13b shows that a low-velocity zone is generated at the central portion of the combustion chamber, with an approximate velocity of $3 \mathrm{~m} / \mathrm{s}$, which is surrounded by a higher velocity zone. It is also observed that there is a rotation of the flow 
at the central zone of the combustor compared to the flow at the liner walls; moreover, the fresh air entering the flame tube has a higher velocity than the model with the optimized swirler.

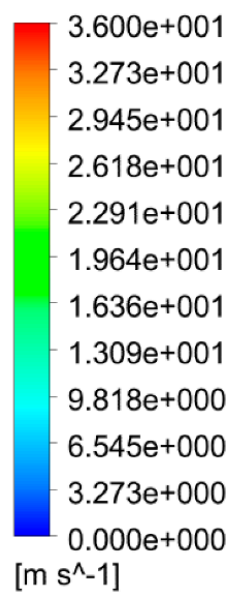

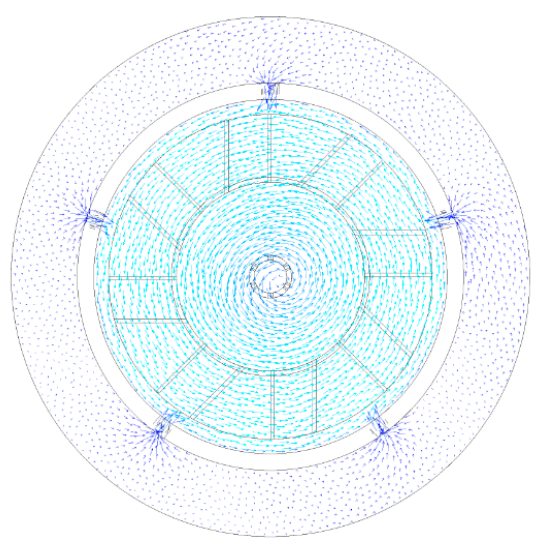

a)

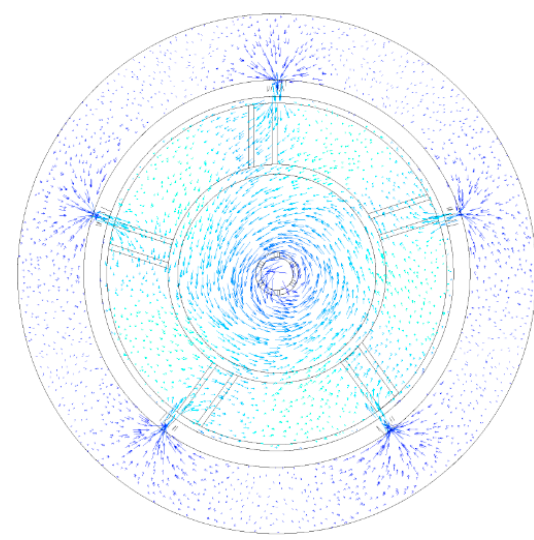

b) peephole 2.

Figure 13. Velocity vectors during combustion in plane 3 of the combustion chamber. (a) Optimized swirler, (b) baseline swirler.

Figure 14, Figure 15, and Figure 16 show the vectors of planes 4, 5, and 6 of the combustion chamber; Figure 14a, Figure 15a, and Figure 16a represent the optimized swirler, and Figure 14b, Figure 15b, and Figure 16b correspond to the baseline swirler. Figure 14a, Figure 15a, and Figure 16a show that the velocity profile pattern in the transverse plane remains constant and rotating inside the flame tube; furthermore, it is observed that air flow enters through the tertiary holes of the combustor and peephole 2. On the other hand, in Figure 14b, Figure 15b, and Figure 16b, it is observed that the flow field does not have a constant velocity pattern along the flame tube; instead, low-velocity zones and a low-intensity rotating flow is given, even though flow also enters through the tertiary holes and

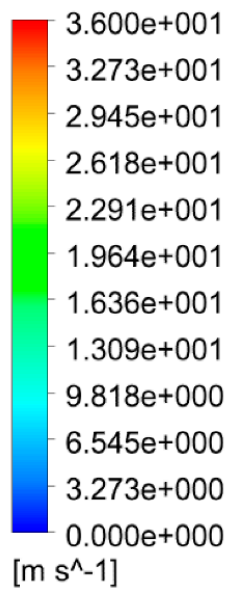

Figure 14. Velocity vectors during combustion in plane 4 of the combustion chamber. (a) Optimized swirler, (b) baseline swirler.

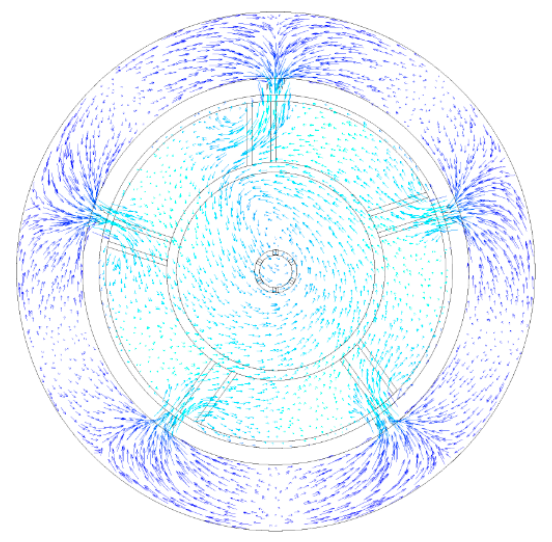

b)

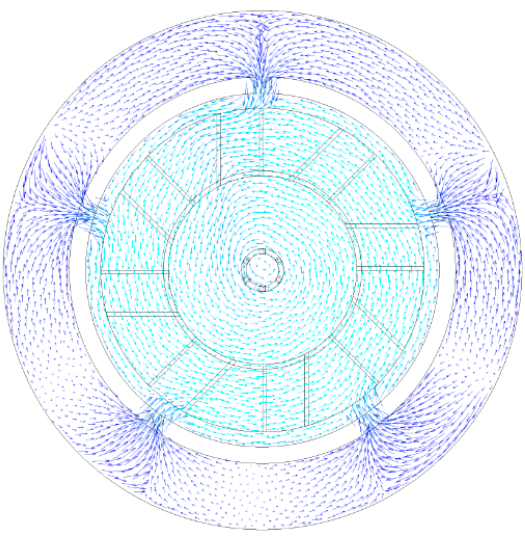

a) $\left[\mathrm{m} \mathrm{s} \mathrm{s}^{\wedge}-1\right]$ 


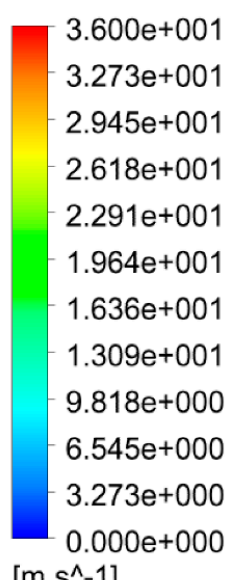
$\left[\mathrm{m} \mathrm{s}^{\wedge}-1\right]$

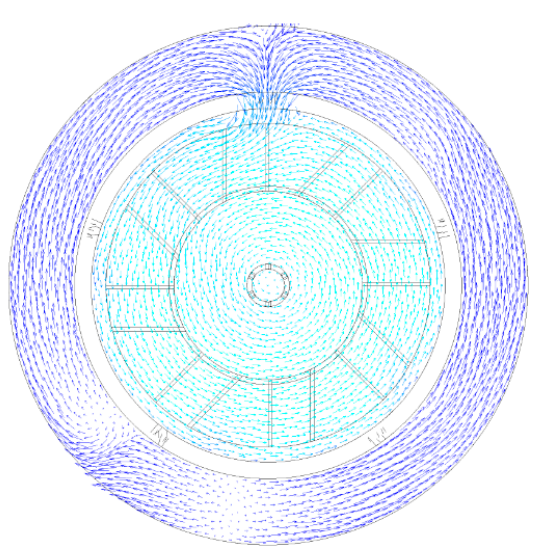

a)

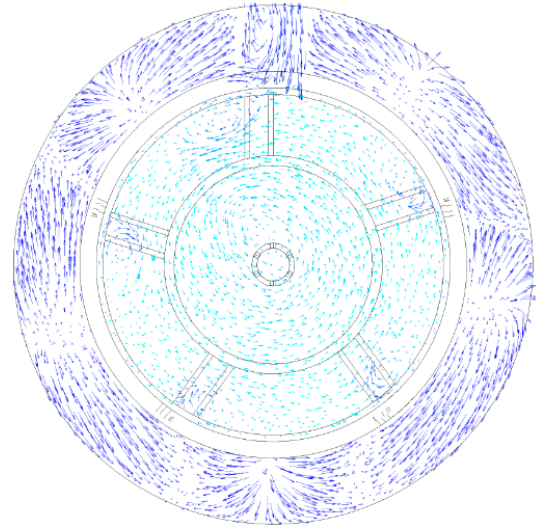

b)

Figure 15. Velocity vectors during combustion in plane 5 of the combustion chamber. (a) Optimized swirler, (b) baseline swirler.

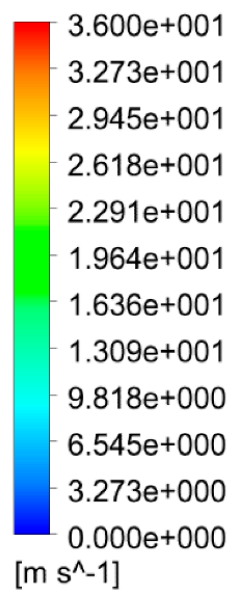

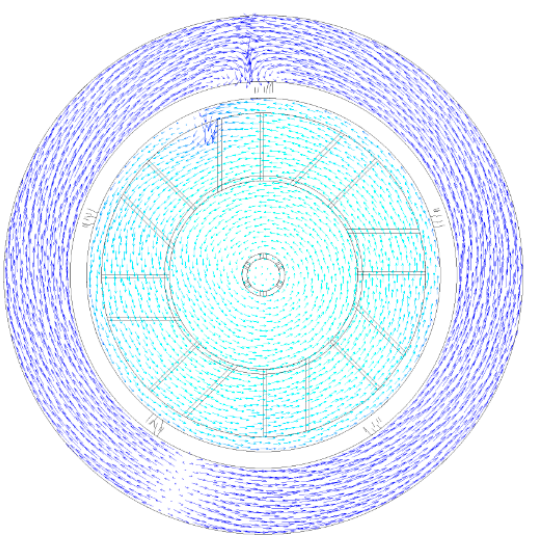

a)

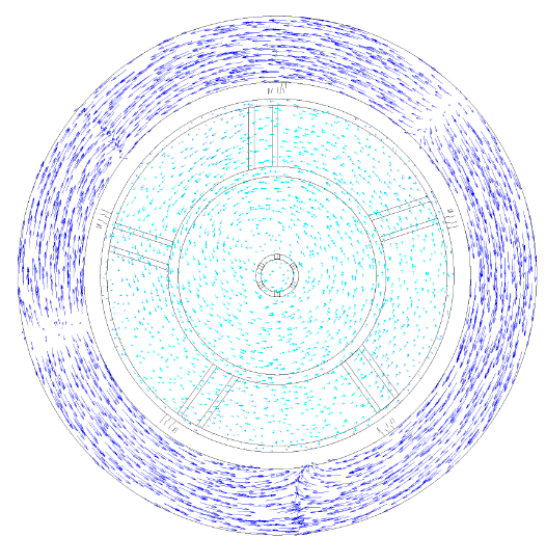

b)

Figure 16. Velocity vectors during combustion in plane 6 of the combustion chamber. (a) Optimized swirler, (b) baseline swirler.

A pressure drops comparison of the air flow circulating through both optimized and baseline swirlers is shown in Figure 17. Figure 17a shows an air flow pressure at the optimized swirler inlet with an average value of $616 \mathrm{~Pa}$; meanwhile, the same variable measured at the outlet has an average value of $587 \mathrm{~Pa}$, as shown in Figure 17b. Pressure drop is created mainly on the swirler internal walls with an average value of $29 \mathrm{~Pa}$; such value is compared with the reference value of Table 4 of $20 \mathrm{~Pa}$. This represents an acceptable approximation to be used with the GA. On the other hand, from Figure 17c-d, it is observed that the baseline swirler has the following values: an inlet pressure of $616 \mathrm{~Pa}$ and an outlet pressure of $530 \mathrm{~Pa}$. Therefore, the pressure drop is $86 \mathrm{~Pa}$, which represents a higher value than the reference in Table 4.

The temperature profile in all six $x y$ planes of the combustion chamber model using the optimized swirler are shown in Figure 18. Figure 18a shows the temperature distribution in the primary zone of the combustion chamber where an annular shaped high-temperature zone is developed around the fuel injector limited by the hub of the swirler. At plane 1, we observe a region with a local mixture with the highest fuel flow fraction, and it generates the highest temperature region matching the highest velocities, while at the lower velocity zones, the temperature decreases. Figure $18 \mathrm{~b}$ shows that the highest local temperature is close to $1200 \mathrm{~K}$ and is located at the central low-velocity zone caused by a local air-fuel mixture with the highest fuel flow fraction in this plane. Figure 18c depicts that highest global temperature is close to $1790 \mathrm{~K}$ located at the center of the combustion chamber, where the local air-fuel mixture has the highest fuel flow fraction, matching in this case with the low-velocity zone. 
In Figure 18d, a decrement in temperature at the combustor core is observed, which is caused mainly by fresh air entering the tertiary holes, obtaining a highest local temperature close to $1450 \mathrm{~K}$. Figure $18 \mathrm{e}, \mathrm{f}$ show the dilution zone with a reduction in the global temperature; comparison between planes 5 and 6 reveals a similar temperature profile corresponding with both planes having a similar velocity profile.

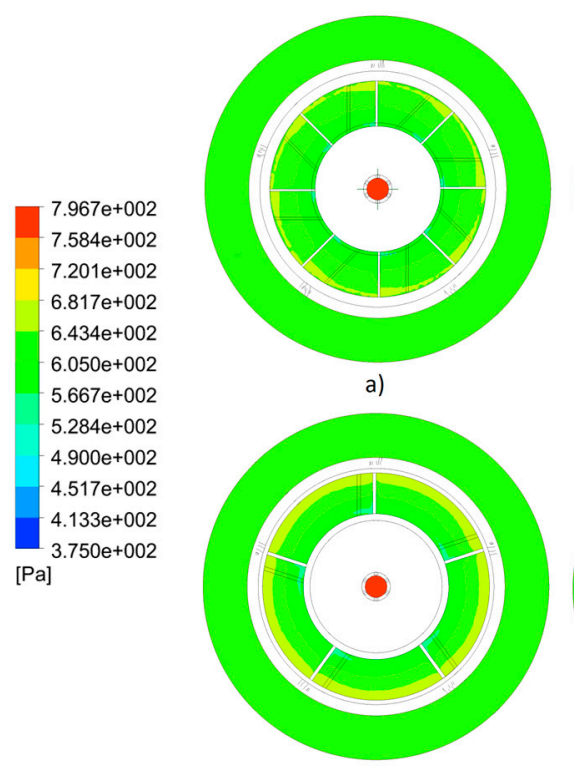

c)

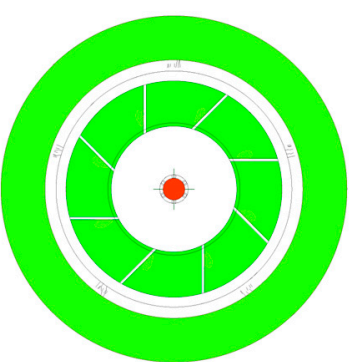

b)

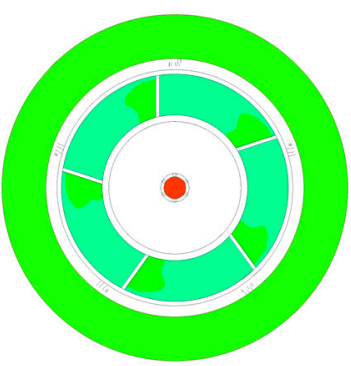

d)

Figure 17. Pressure drop of the air flow generated by the swirler. (a) Pressure at the optimized swirler inlet, (b) pressure at the optimized swirler outlet, (c) pressure at the baseline swirler inlet, (d) pressure at the baseline swirler outlet.

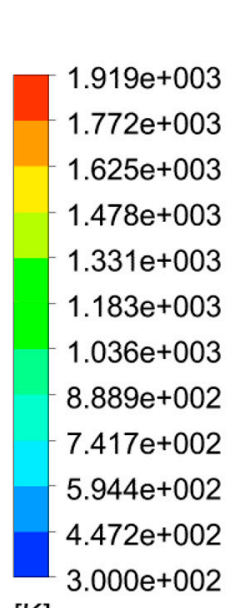

[K]

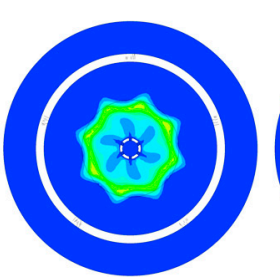

a)

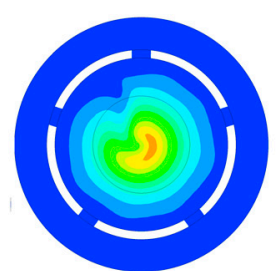

d)

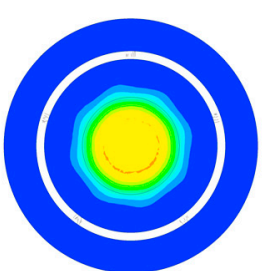

b)

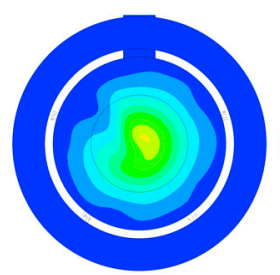

e)

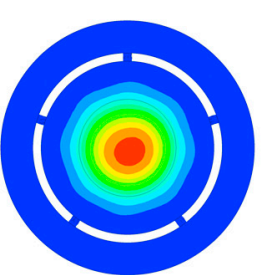

c)

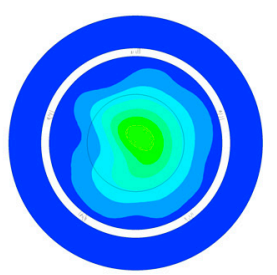

f)

Figure 18. Results of temperature profile in different $x y$ planes of a CFD model of a combustion chamber with optimized swirler. (a) Plane $1(10.50 \mathrm{~cm})$, (b) plane $2(14 \mathrm{~cm}),(\mathbf{c})$ plane $3(17.60 \mathrm{~cm})$, (d) plane 4 $(23.60 \mathrm{~cm}),(\mathbf{e})$ plane $5(26.60 \mathrm{~cm})$, and $(\mathbf{f})$ plane $6(30 \mathrm{~cm})$.

Figure 19 shows the temperature profile in all six $x y$ planes of the combustion chamber model with the baseline swirler. Figure 19a contains the highest global temperature with approximately $1900 \mathrm{~K}$ located at a low-velocity star-like shaped zone as in Figure 11b, while the lower local temperatures match the high-velocity zones; for this plane, a local air-fuel mixture with the highest fuel flow fraction is found at the aforementioned star-like shape. In Figure 19b, the global temperature decreases with values up to $1480 \mathrm{~K}$ corresponding to a decrease in the fuel flow fraction; this behavior matches the 
increment in flow velocity, keeping a similar shape as in plane 1. Figure 19c shows that the air flow coming from secondary holes makes the temperature decrease to an average value of $900 \mathrm{~K}$, given that at this plane, a low-velocity zone is kept at the center of the flame tube. Figure $19 \mathrm{~d}-\mathrm{f}$ depict temperature profiles with approximate values of $740 \mathrm{~K}$.

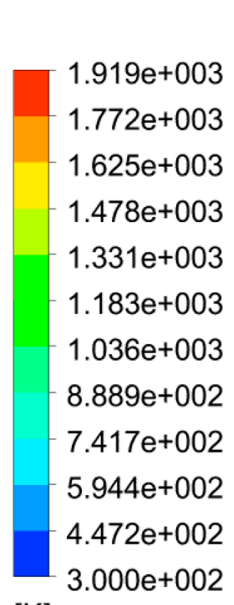

$[\mathrm{K}]$

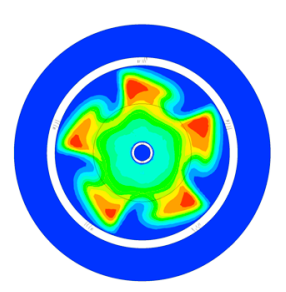

a)

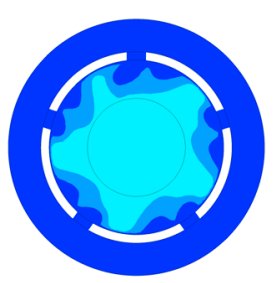

d)

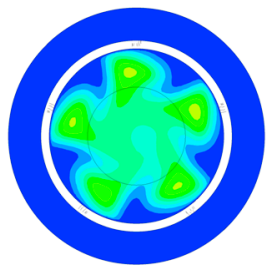

b)

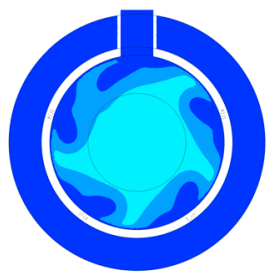

e)

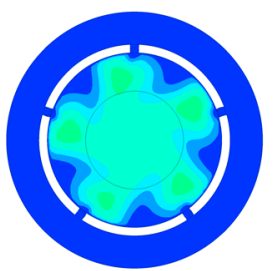

c)

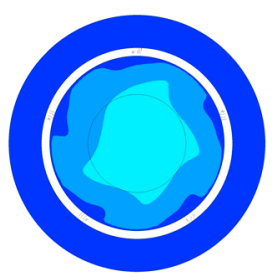

f)

Figure 19. Results of temperature profile in different $x y$ planes of a CFD model of a combustion chamber with a baseline swirler. (a) Plane $1(10.50 \mathrm{~cm}),($ b) plane $2(14 \mathrm{~cm}),(\mathbf{c})$ plane $3(17.60 \mathrm{~cm}),(\mathrm{d})$ plane 4 $(23.60 \mathrm{~cm}),(\mathrm{e})$ plane $5(26.60 \mathrm{~cm})$, and $(\mathrm{f})$ plane $6(30 \mathrm{~cm})$.

Figure 20 shows the mole fraction of the $\mathrm{CO}$ profile in all six $x y$ planes of the combustion chamber model using the optimized swirler. Figure 20a shows a symmetric distribution of the mole fraction of $\mathrm{CO}$ at the center of the plane, where $\mathrm{CO}$ appears as a result of fuel burning. Figure 20b depicts plane 2 corresponding to the primary zone of the combustion chamber where the highest global mole fraction of $\mathrm{CO}$ is located at the combustion core. Figure 20c describes plane 3 containing mainly a cross-section of the secondary zone; it can be observed that the mole fraction of $\mathrm{CO}$ decreases as an effect of fresh air entering from the secondary holes, allowing $\mathrm{CO}$ to oxidize and form $\mathrm{CO}_{2}$. Figure $20 \mathrm{~d}$ shows a significant reduction in mole fraction of $\mathrm{CO}$, while in Figure 20e,f, the formation of $\mathrm{CO}$ reaches its minimum.

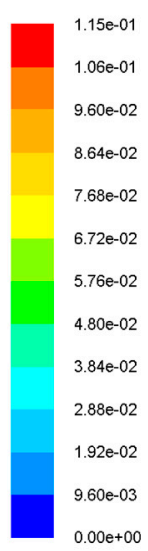

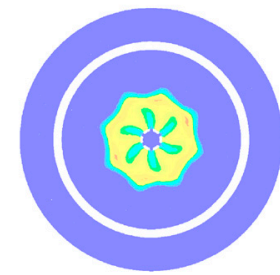

a)

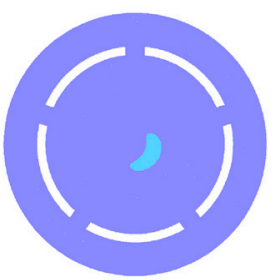

d)

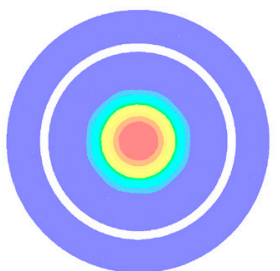

b)

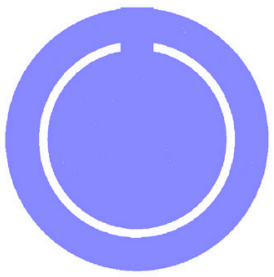

e)

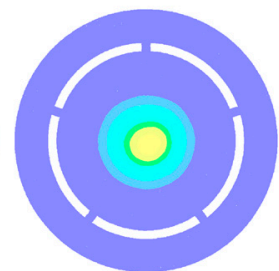

c)

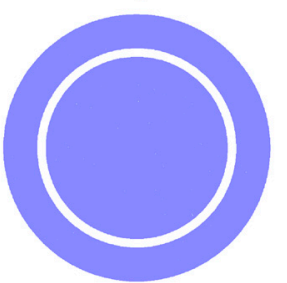

f)

Figure 20. Results of mole fraction of CO profile in different $x y$ planes of a CFD model of a combustion chamber with an optimized swirler. (a) Plane $1(10.50 \mathrm{~cm}),(\mathbf{b})$ plane $2(14 \mathrm{~cm}),(\mathrm{c})$ plane $3(17.60 \mathrm{~cm})$, (d) plane $4(23.60 \mathrm{~cm}),($ e) plane $5(26.60 \mathrm{~cm})$, and $(\mathbf{f})$ plane $6(30 \mathrm{~cm})$. 
In Figure 21, the mole fraction of CO generated during combustion with the baseline swirler is visualized. Figure 21a shows the mole fraction of $\mathrm{CO}$ in plane 1 keeping a star-like shape as in the low-velocity zone shown in Figure 11, indicating that combustion happens in this zone. The mole fraction of $\mathrm{CO}$ in planes 2-6 is minimal, as there is no CO generation as shown in Figure 21b-f.

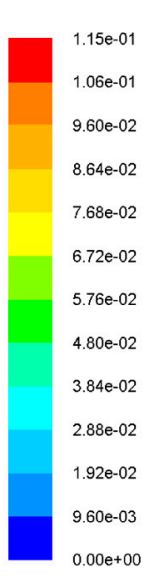

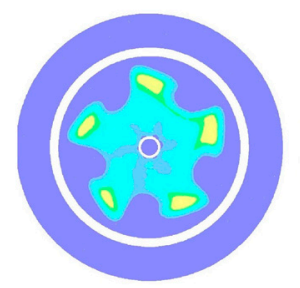

a)

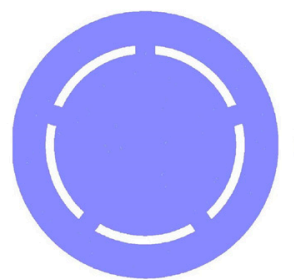

d)

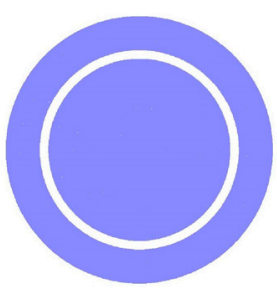

b)

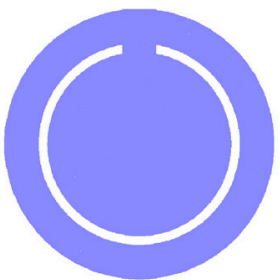

e)

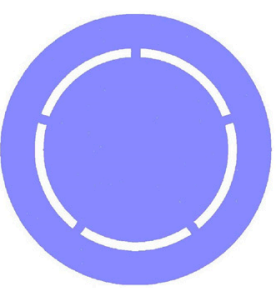

c)

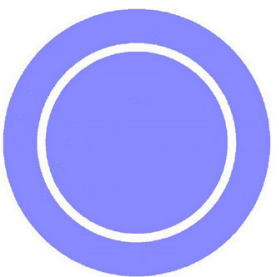

f)

Figure 21. Results of mole fraction of CO profile in different $x y$ planes of a CFD model of a combustion chamber with a baseline swirler. (a) Plane $1(10.50 \mathrm{~cm}),(\mathbf{b})$ plane $2(14 \mathrm{~cm}),(\mathbf{c})$ plane $3(17.60 \mathrm{~cm})$, (d) plane $4(23.60 \mathrm{~cm}),($ e) plane $5(26.60 \mathrm{~cm})$, and (f) plane $6(30 \mathrm{~cm})$.

Figure 22 shows the mole fraction of the $\mathrm{CO}_{2}$ profile resulting from using the optimized swirler in the six reference planes used to describe the combustion chamber. Figure 22a shows the $\mathrm{CO}_{2}$ generated when fuel starts to burn, getting a symmetric pattern around the fuel injector. A mole fraction of $\mathrm{CO}_{2}$ with an annular shape is observed at the core area of plane 2 in Figure 22b. Figure 22c describes the behavior of the secondary zone in the combustion chamber where the highest global mole fraction of $\mathrm{CO}_{2}$ is obtained matching the plane with the highest global temperature; this phenomenon is the result of $\mathrm{CO}$ reacting with oxygen entering from the secondary holes to produce $\mathrm{CO}_{2}$. Figure 22d-f depict the dilution zone as the mole fraction of $\mathrm{CO}_{2}$ decreases closer to the combustion chamber outlet caused by air flowing through tertiary holes and peephole 2; $\mathrm{CO}_{2}$ has an uniform distribution across the planes.

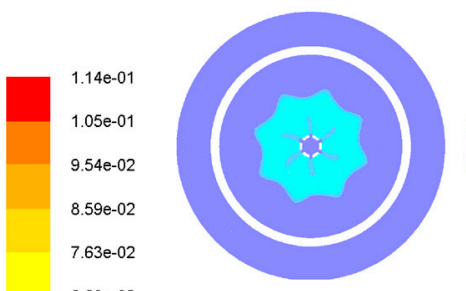

a)

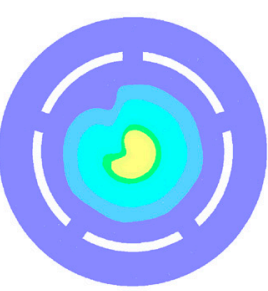

d)

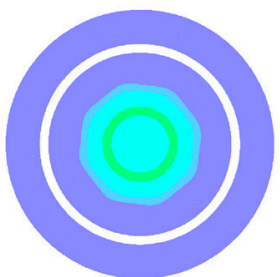

b)

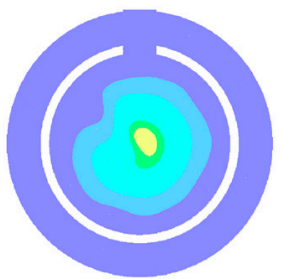

e)

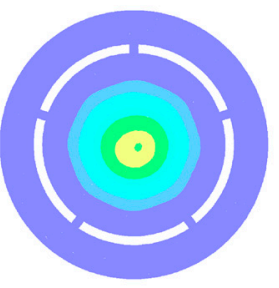

c)

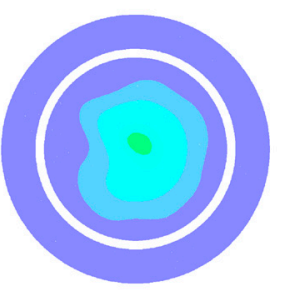

f)

Figure 22. Results of mole fraction of a $\mathrm{CO}_{2}$ profile in different $x y$ planes of a CFD model of a combustion chamber with an optimized swirler. (a) Plane $1(10.50 \mathrm{~cm}),(\mathbf{b})$ plane $2(14 \mathrm{~cm})$, (c) plane $3(17.60 \mathrm{~cm})$, (d) plane $4(23.60 \mathrm{~cm})$, (e) plane $5(26.60 \mathrm{~cm})$, and $(\mathbf{f})$ plane $6(30 \mathrm{~cm})$. 
The mole fraction of $\mathrm{CO}_{2}$ distribution obtained with the baseline swirler is given in Figure 23. Figure 23a demonstrates that the highest global mole fraction of $\mathrm{CO}_{2}$ has a star-like shape similar to the behavior of $\mathrm{CO}$ distribution across this plane, as shown in Figure 21a. Figure 23b shows how the star-like shape is preserved; however, the mole fraction of $\mathrm{CO}_{2}$ decreases. In plane 3 (Figure 23c), the mole fraction of $\mathrm{CO}_{2}$ decreases, given that fuel flow was burnt at the two previous planes. In Figure 23d-f, the mole fraction of $\mathrm{CO}_{2}$ is uniform and keeps decreasing closer to the combustion chamber outlet.

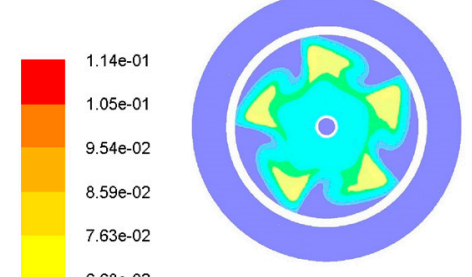

a)

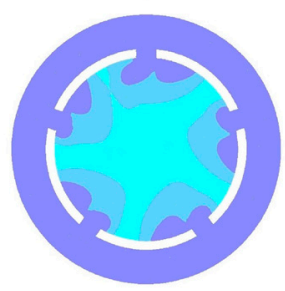

d)

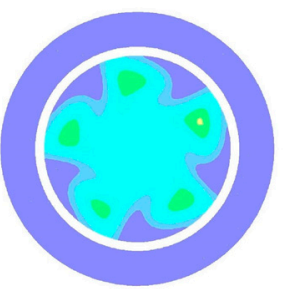

b)

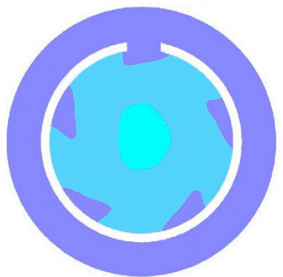

e)

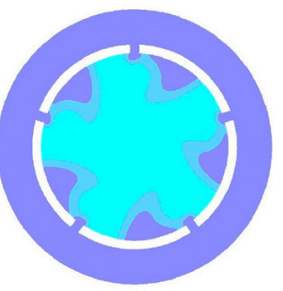

c)

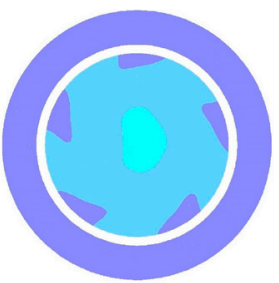

f)

Figure 23. Results of mole fraction of the $\mathrm{CO}_{2}$ profile in different $x y$ planes of the CFD model of a combustion chamber with a baseline swirler. (a) Plane $1(10.50 \mathrm{~cm}),(\mathrm{b})$ plane $2(14 \mathrm{~cm})$, (c) plane 3 $(17.60 \mathrm{~cm}),(\mathbf{d})$ plane $4(23.60 \mathrm{~cm}),(\mathbf{e})$ plane $5(26.60 \mathrm{~cm})$, and $(\mathbf{f})$ plane $6(30 \mathrm{~cm})$.

\subsection{Experimental Results}

Once the objectives of the optimized swirler were verified with the numerical analysis, the combustion experimental tests were carried out to compare the numerical data with the experimental data and validate them.

A swirler prototype was used to measure the temperature behavior inside a combustion chamber. For these measurements, the following conditions were employed: atmospheric pressure of 101,325 $\mathrm{Pa}$, ambient temperature of $303 \mathrm{~K}$, air supply temperature of $305 \mathrm{~K}$, fuel pressure of $2275 \mathrm{~Pa}$, and fuel temperature of $300 \mathrm{~K}$. Figure 24 shows the combustion chamber with its main components.

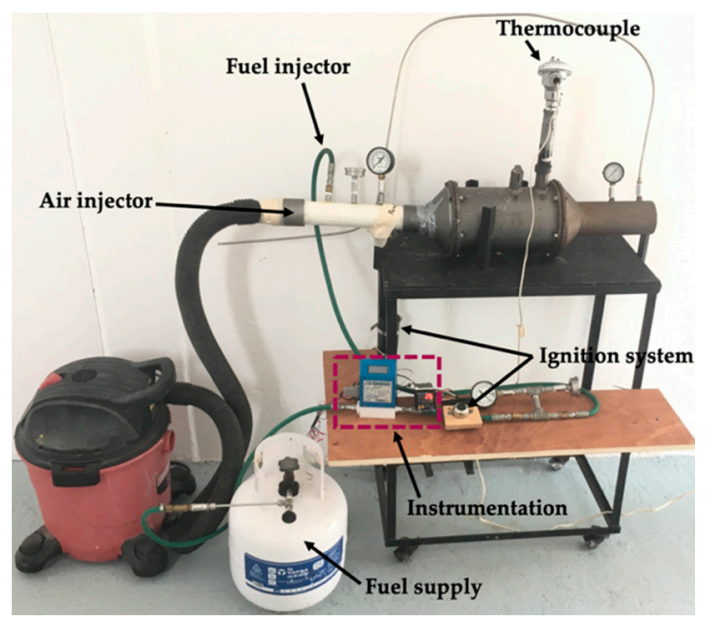

Figure 24. Prototype of combustion chamber used in experimental tests. 
The temperature inside the combustion chamber was measured using a bimetallic thermocouple (platinum-rhodium 13\%), which allows obtaining temperature measurements ranging from 0 to $1450{ }^{\circ} \mathrm{C}$ with an uncertainty of $+/-1.5^{\circ} \mathrm{C}$. It has a ceramic insulating bar of $30 \mathrm{~cm}$ length and a ceramic cover. The thermocouple was positioned in two peepholes of the combustion chamber at four different positions. The reference for placing the thermocouple was the central axis of the combustion chamber. Figure 25 depicts the thermocouple positions in both peepholes.

a)

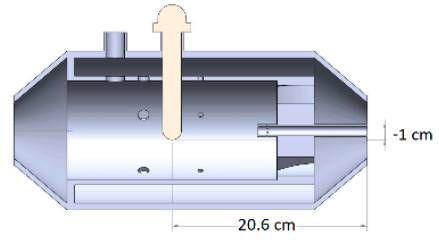

b)

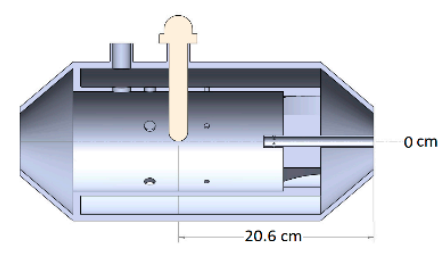

c)

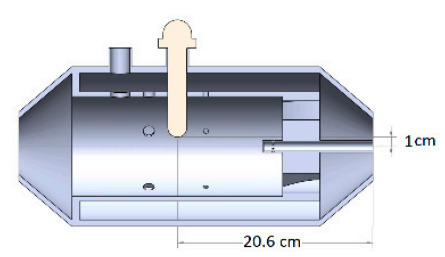

d)

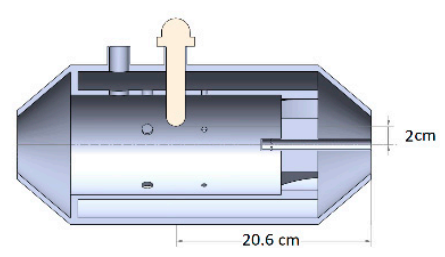

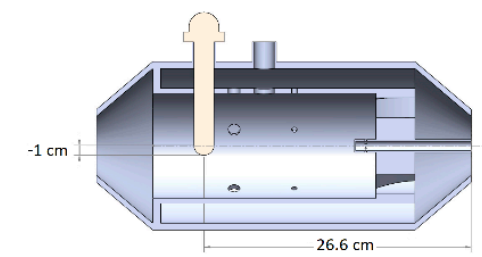

f) $0 \mathrm{~cm}$

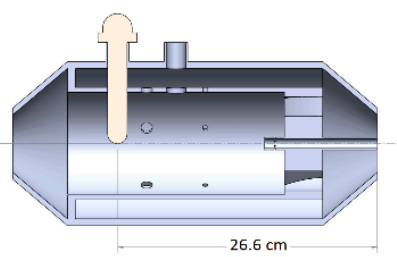

g)

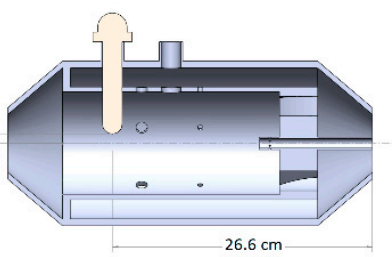

h) $2 \mathrm{~cm}$

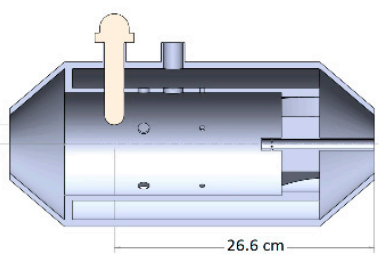

Figure 25. Schematic view of different positions of thermocouple in peephole 1 (left): (a) Position 1, (b) position 2, (c) position 3, and (d) position 4, and peephole 2 (right): (e) position 1, (f) position 2, (g) position 3 , and (h) position 4.

Figure 26 shows the measurements of temperature in four different positions of the combustion chamber. For peephole 1, the highest temperature was measured in position 1 with average temperatures of $1002 \mathrm{~K}$. On the contrary, the lowest temperature was registered in position 4 with average value of $438 \mathrm{~K}$. For peephole 2, the highest temperature $(1030 \mathrm{~K})$ was achieved in position 1 and the lowest temperature $(438 \mathrm{~K})$ was measured in position 4. 


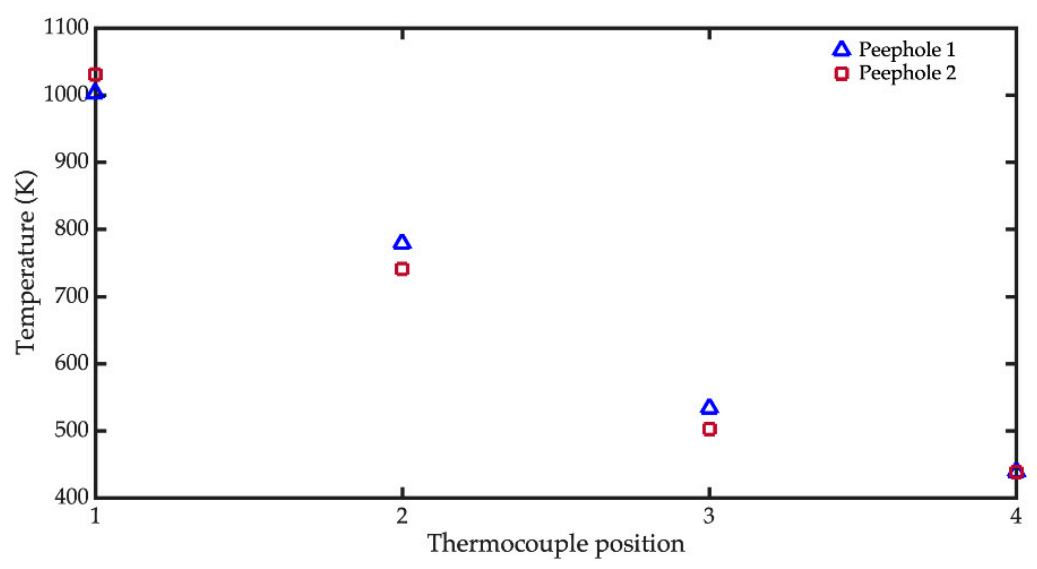

Figure 26. Measurements of temperatures in four different positions of the combustion chamber.

\section{Validation of Numerical Modeling}

Figure 27 shows the temperature results obtained using the CFD model and experimental tests in peephole 1 of the combustion chamber. The numerical results of the temperature agree well with the measurement results. Figure 28 depicts the numerical and experimental values of temperature in four different positions along peephole 2 of the combustion chamber. The numerical values of the temperature agree well in comparison with measurement results.

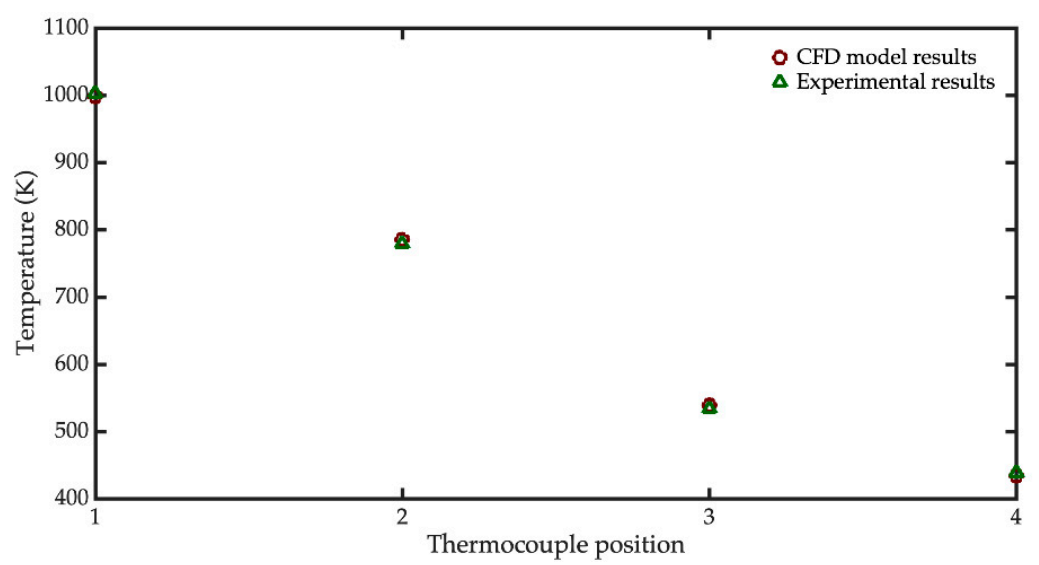

Figure 27. Temperature in peephole 1 obtained using a CFD model and experimental tests.

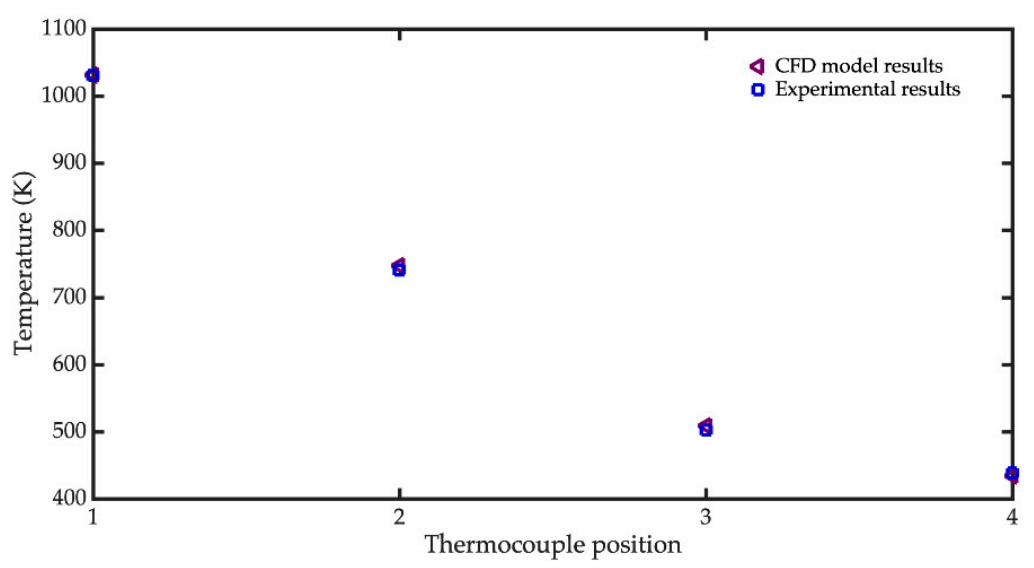

Figure 28. Temperature in peephole 2 obtained using a CFD model and experimental tests. 
An infrared thermographic camera (Fluke) was used to visualize the distribution of temperature at the outlet of the combustion chamber. The thermographic camera has a spatial resolution of $320 \times 240$ and it was configured as follows: emissivity 0.95, bottom temperature of $308.15 \mathrm{~K}$, and transmission of $100 \%$. Figure 29 shows the measurement of the temperature distribution at the exterior environment of the combustion chamber. Low temperature is registered at the walls of the flame tube, while the area of the nozzle outlet reaches the maximum temperature of $557 \mathrm{~K}$. In addition, Figure 30 depicts a thermal image of a cross-section at the combustion chamber outlet. It registers the temperature profile, in which the highest temperature $(638 \mathrm{~K})$ is located at the center of the combustion chamber. However, the internal walls of the combustion chamber have relatively low temperatures. Due to this, the generation of hot spots inside the combustor is decreased.

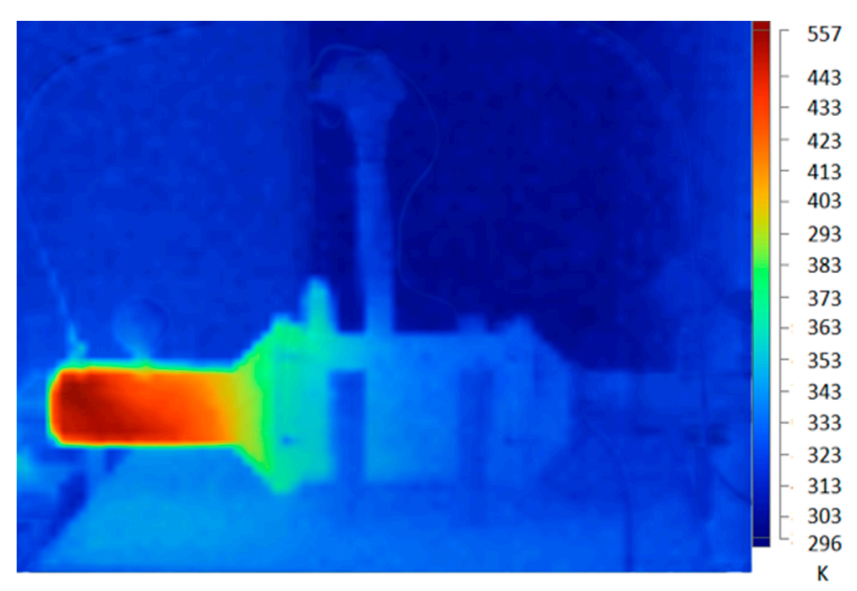

Figure 29. Lateral thermal image of the combustion chamber.

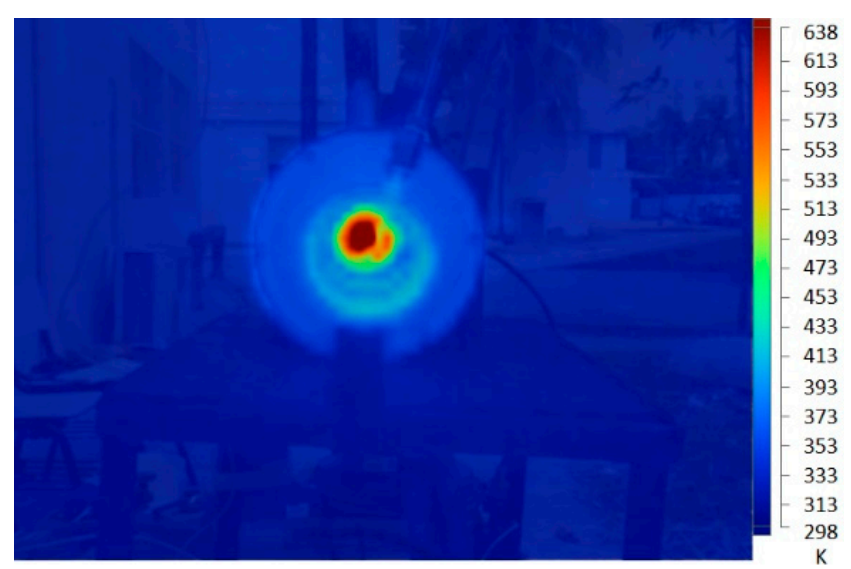

Figure 30. Cross thermal image of the combustion chamber outlet.

\section{Conclusions}

The optimized design of a swirler using genetic algorithms to generate a recirculation zone in a combustion chamber was presented. CFD models of the combustion chamber were developed using ANSYS software (16.2, ANSYS, Inc., Pittsburgh, USA) through the FLUENT module. In these models, the renormalization group (RNG) $k-\varepsilon$ turbulence method was applied. The optimized design was compared to a baseline design to verify optimization. Results obtained numerically showed that the optimized swirler generates a recirculation zone with a longer length and less width. The flame obtained using the optimized swirler was located at the center of the combustion chamber, while using the baseline swirler, a flame was found upstream from the aforementioned location. The exhaust temperature using the optimized swirler was higher than its baseline counterpart, even though the same air-fuel ratio was used. 
The CFD models of the combustion chamber using the optimized swirler showed that the stabilization was sensitive to the recirculation zone. In addition, the temperature behavior obtained using the CFD models agreed well in comparison with the experimental results. The Thermographic images showed that the external walls of the combustion chamber registered low-temperature values.

The prediction of the recirculation generated by the experimentally proposed swirler is beyond the scope of this investigation; however, the implementation of the use of particle image velocimetry (PIV) in future research is proposed to obtain parameters such as radial and axial velocities and the swirl number produced by the proposed swirler.

Author Contributions: CFD models of combustion chamber and experimental data, D.A.Z.-L. and M.E.T.-d.-C.; methodology, M.O.V.-Z.; writing-review and editing, A.L.H.-M.; materials, S.A.Z.-C. All authors have read and agreed to the published version of the manuscript.

Funding: The APC was funded by the Master in Applied Engineering of Veracruzana University.

Acknowledgments: Daniel Alejandro Zavaleta-Luna thanks to Consejo Nacional de Ciencia y Tecnología by the scholarship received during his master studies.

Conflicts of Interest: The authors declare no conflict of interest. The funders had no role in the design of the study; in the collection, analyses, or interpretation of data; in the writing of the manuscript, or in the decision to publish the results.

\section{References}

1. Hong, S.; Shanbhogue, S.J.; Ghoniem, A.F. Impact of Fuel Composition on the Recirculation Zone Structure and its Role in Lean Premixed Flame Anchoring. Proc. Combust. Inst. 2015, 35, 1493-1500. [CrossRef]

2. Weigand, P.; Meier, W.; Duan, X.R.; Stricker, W.; Aigner, M. Investigations of Swirl Flames in a Gas Turbine Model Combustor: I. Flow field, structures, temperature, and species distributions. Combust. Flame 2006, 144, 205-224. [CrossRef]

3. Durox, D. Flame Dynamics of a Variable Swirl Number System and Instability Control. Combust. Flame 2013, 160, 1729-1742. [CrossRef]

4. Krieger, G.C.; de Campos, A.P.V.; Filho, F.L.S.; de Souza, R.C. A Swirler Stabilized Combustion Chamber for a Micro-Gas Turbine Fuelled with Natural Gas. J. Braz. Soc. Mech. Sci. Eng. 2012, 34, 441-449. [CrossRef]

5. Zainul, M.N.M.; Jaafar, M.N.M.; Lazim, T.M. Effect of Varying the Double Radial Swirler Configuration on the Fluid Dynamic and Emissions Performances in a Can Combustor. J. Teknol. 2017, 79, 33-41. [CrossRef]

6. Tuma, J.; Kubata, J.; Betak, V.; Hybl, R. Experimental and Numerical Research of a Novel Combustion Chamber. Eur. Phys. J. Conf. 2013, 45, 1091. [CrossRef]

7. Lefebvre, A.H.; Ballal, D.R. Gas Turbine Combustion Alternative Fuels and Emissions, 3rd ed.; CRC Press: Boca Raton, FL, USA, 2010.

8. Fernández, P.D. Control y Eliminación de los NOx. Cent. Térmicas 2000, 2, 945-961.

9. Syred, N. A Review of Oscillation Mechanisms and the Role of the Precessing Vortex Core (PVC) in Swirl Combustion Systems. Prog. Energy Combust. Sci. 2006, 32, 93-161. [CrossRef]

10. Mundus, B.; Kremer, H. The Influence of Swirl Generator Characteristics on Flow and Combustion in Turbulent Diffusion Flames. Aerothermodyn. Combustors 1992, 89-103. [CrossRef]

11. Kwark, J.H.; Jeong, Y.K.; Jeon, C.H.; Chang, Y.J. Effect of Swirl Intensity on the Flow and Combustion of a Turbulent Non-Premixed Flat Flame. Flow Turbul. Combust. 2005, 73, 231-257. [CrossRef]

12. Kumar, S.; Pandey, K.M. Computational Simulation and Effect of Swirl Angle on NOx Generation of 2D Swirl Burner in Gas Turbine. IJERT 2014, 3, 1243-1246.

13. Ruan, C.; Chen, F.; Yu, T.; Cai, W.; Li, X.; Lu, X. Experimental Study on Flame/Flow Dynamics in a Multi-Nozzle Gas Turbine Model Combustor Under Thermo-Acoustically Unstable Condition with Different Swirler Configurations. Aerosp. Sci. Technol. 2020, 98, 105692. [CrossRef]

14. Tanimura, S.; Nose, M.; Ishizaka, K.; Takiguchi, S.; Rodriguez, J. Advanced Dry Low NOx Combustor for Mitsubishi G Class Gas Turbines. Combust. Fuels Emiss. Parts A B 2008, 3, 607-615.

15. Rodríguez, N.P.; Tamariz, E.R.; Illescas, R.G. Emissions and Noise Pollution Diagnosis of a Turbogas Power Plant During Commissioning Service. Combust. Fuels Emiss. Parts A B 2010, 2, 1269-1276.

16. Júnior, J.A.C.; Lacava, P.T. Emissões Em Processos de Combustão, 1st ed.; Unesp: São Paulo, Brazil, 2003. 
17. Cerutti, M. Dry Low NOx Emissions Operability Enhancement of a Heavy-Duty Gas Turbine by Means of Fuel Burner Design Development and Testing. In Proceedings of the ASME Turbo Expo 2018: Turbomachinery Technical Conference and Exposition, Oslo, Norway, 11-15 June 2018.

18. Tuttle, S.G. Lean Blowoff Behavior of Asymmetrically-Fueled Bluff Body-Stabilized Flames. Combust. Flame 2013, 160, 1677-1692. [CrossRef]

19. Tejeda-del-Cueto, M.E.; Vigueras, M.O.Z.; Welsh, C.M.R.; Ordoñez, C.L.R.; Marin, L.F.U.; Herrera, A.L.M. Alineamiento de Flama Usando Placas Perforadas Tándem en una Cámara de Combustión de Gas LP. Ing. Mecánica. Tecnol. Desarro. 2015, 5, 293-302.

20. Kilik, E. The Influence of Swirler Design Parameters on the Aerodynamics of Downstream Recirculation Region. Ph.D. Thesis, School of Mechanical Engineering, Cranfield Institute of Technology, Cranfield, UK, May 1976.

21. Valera, A.M. Ammonia-Methane Combustion in Tangential Swirl Burners for Gas Turbine Power Generation. Appl. Energy 2017, 185, 1362-1371. [CrossRef]

22. Khadase, R.D.; Bhele, S.K. Performance Evaluation of Combustor by Using Different Swirler. Int. J. Res. Appl. Sci. Eng. Technol. 2016, 4, 85-90.

23. Gupta, N.; Lilley, A.K.; Syred, D.G. Swirl Flows; Abacus Press: Turnbridge Wells, UK, 1984.

24. Archer, S.; Gupta, A.K. Swirl Effects on Global and Chemical Behavior of Flames. In Proceedings of the Intersociety Energy Conversion Engineering Conference, Washington, WA, USA, 29-31 July 2002; pp. 364-369.

25. Andrews, G.E.; Ahmad, N.T. Axial Swirler Design Influences on NOx Emissions for Premixed Combustion in Gas Turbine Combustors with All the Combustor Air Flow Passing Through the Swirler. Proc. ASME Turbo Expo 2011, 2, 449-460.

26. Sander, G.F. Axial Vane-Type Swirler Performance Characteristics Axial Vane-Type Swirler Performance Characteristics. Master's Thesis, Oklahoma State University, Stillwater, OK, USA, July 1983.

27. Thundil, R.K.R.; Ganesan, V. Study on the Effect of Various Parameters on Flow Development behind Vane Swirlers. Int. J. Therm. Sci. 2008, 47, 1204-1225. [CrossRef]

28. Mularz, E.J. Flow Characteristics of Various Swirl-Can Module Designs. NASA: Washington, DC, USA, 1975; Volume 3236, pp. 1-37.

29. Khandelwal, B.; Banjo, O.; Sethi, V. Design, Evaluation and Performance Analysis of Staged Low Emission Combustors. ASME J. Eng. Gas Turbines Power 2014, 136, 1-11. [CrossRef]

30. Bourgouin, J.F.; Moeck, J.; Durox, D.; Schuller, T.; Candel, S. Sensitivity of Swirling Flows to Small Changes in the Swirler Geometry. Comptes Rendus Mec. 2013, 341, 211-219. [CrossRef]

31. Gopakumar, R.; Mondal, S.; Paul, R.M.S.; Chaudhuri, S. Mitigating Instability by Actuating the Swirler in a Combustor. Combust. Flame 2016, 165, 361-363. [CrossRef]

32. Khanafer, K.; Aithal, S.M. Fluid-Dynamic and NOx Computation in Swirl Burners. Int. J. Heat Mass Transf. 2011, 54, 5030-5038. [CrossRef]

33. Eldrainy, Y.A.; Saqr, K.M.; Aly, H.S.; Lazim, T.M.; Jaafar, M.N.M. Large Eddy Simulation and Preliminary Modeling of the Flow Downstream a Variable Geometry Swirler for Gas Turbine Combustors. Int. Commun. Heat Mass Transf. 2011, 38, 1104-1109. [CrossRef]

34. Zhou, L.X. Comparison of Studies on Flow and Flame Structures in Different Swirl Combustors. Aerosp. Sci. Technol. 2018, 80, 29-37. [CrossRef]

35. Beer, J.M.; Chigier, N.A. Combustion Aerodynamics; Applied Science Publishers Ltd.: London, UK, 1972.

36. Bhuvana, R.G.; Srinivasan, S.A.; Thanikaivel, D.M. CFD Analysis on Swirl Angle Effect in Gas Turbine Combustion Chamber. IOP Conf. Ser. Mater. Sci. Eng. 2018, 402, 12206. [CrossRef]

37. Matlab, Genetic Algorithm, Help with Matlab Script. Available online: https://www.mathworks.com/ discovery/genetic-algorithm.html (accessed on 9 April 2020).

38. Hiroyasu, H.; Miao, H.; Hiroyasu, T.; Miki, M.; Kamiura, J.; Watanabe, S. Genetic Algorithms Optimization of Diesel Engine Emissions and Fuel Efficiency with Air Swirl, EGR, Injection Timing and Multiple Injections. SAE Tech. Pap. Ser. 2003, 1, 1853.

39. Senecal, P.K.; Pomraning, E.; Richards, K.J. Multi-Mode Genetic Algorithm Optimization of Combustion Chamber Geometry for Low Emissions. SAE Tech. Pap. Ser. 2002, 1, 958.

40. Liu, J.; Wang, J.; Zhao, H. Optimization of the Injection Parameters and Combustion Chamber Geometries of a Diesel/Natural Gas RCCI Engine. Energy 2018, 164, 837-852. [CrossRef]

41. Brizuela, D.I.; Romano, D.; Loza, J.C. Combustión en Turbinas de Gas. Combustión 2007, 8, $132-145$. 
42. Halpin, J.L. Swirl Generation and Recirculation Using Radial Swirl Vanes G. E. Aircraft Engines ornw. Am. Soc. Mech. Eng. 1993, 93, 1-9.

43. Keshtkar, H. The Effect of Flow Pattern on Combustion and Pollution Generation in a Jet Engine. J. Astrophys. Aerosp. Technol. 2018, 6, 1-4. [CrossRef]

44. Martin, C.A. Aspects of the Design of Swirlers as Used in Fuel Injectors for Gas Turbine Combustors. Am. Soc. Mech. Eng. 1987, 87, 139.

45. Beer, M.; Syred, N. Combustion in Swirling Flows: A Review. Combust. Flame 1974, 23, 143-201.

46. Knight, H.A.; Walker, R.B. The Component Pressure Losses in Combustion Chambers. Natl. Gas Turbine Establ. 1953, 143, 65.

47. Khandelwal, B.; Lili, D.; Sethi, V. Design and study on performance of axial swirler for annular combustor by changing different design parameters. J. Energy Inst. 2014, 87, 372-382. [CrossRef]

48. Dina, A.; Danaila, S.; Pricop, M.V.; Bunescu, I. Using genetic algorithms to optimize airfoils in incompressible regime. INCAS Bull. 2019, 11, 79-90. [CrossRef]

49. How the Genetic Algorithm Works - MATLAB \& Simulink - MathWorks América Latina. Available online: https:/la.mathworks.com/help/gads/how-the-genetic-algorithm-works.html (accessed on 18 April 2020).

50. Bahr, D.W. Combustion System Design; Mello, A.M., Ed.; Academic Press: San Diego, CA, USA, 1990.

51. Martin, C.A. Air Flow Performance of Air Swirlers for Gas Turbine Fuel Nozzles. In Proceedings of the ASME 1988 International Gas Turbine and Aeroengine Congress and Exposition, Amsterdam, The Netherlands, 6-9 June 1988.

52. Yakhot, V.; Orszag, S.A. Renormalization group analysis of turbulence. I. Basic theory. J. Sci. Comput. 1986, 1, 3-51. [CrossRef]

53. ANSYS Inc. ANSYS CFX-Solver Modeling Guide v14.0; ANSYS Inc.: Canonsburg, PA, USA, 2011; Volume 15317.

54. Vondál, J.; Hájek, J. Prediction of Flow through Swirl Generator and Validation by Measured Data. J. Phys. Conf. Ser. 2011, 318, 022026. [CrossRef]

55. Liu, Y.L.; Tang, H. Numerical Study on the Interaction Mechanism between Swirl and Reverse Flow Rate in a Twin Swirl Combustor. Adv. Mater. Res. 2014, 960-961, 341-348. [CrossRef]

56. Breussin, F.; Pigari, F.; Weber, R. Predicting the near-burner-one flow field and chemistry of swirl-stabilized

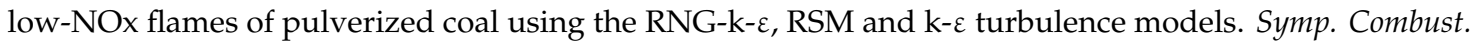
1996, 26, 211-217. [CrossRef]

57. Darmawan, S.; Budiarso, B.; Siswantara, A.I. CFD Investigation of Standard k-and RNG k-Turbulence Model in Compressor Discharge of Proto X-2 Bioenergy Micro Gas Turbine. In Proceedings of the 8th International Conference in Fluid Thermal and Energy Conversion, Semarang, Indonesia, 9-10 November 2013; pp. 4-8.

58. Mompean, G. Numerical simulation of a turbulent flow near a right-angled corner using the speziale non-linear model with RNG K- $\varepsilon$ equations. Comput. Fluids 1998, 27, 847-859. [CrossRef]

59. Carbonell, D.; Oliva, A.; Perez, C.D. Implementation of two-equation soot flamelet models for laminar diffusion flames. Combust. Flame 2009, 156, 621-632. [CrossRef]

60. Peters, N. Multiscale Combustion and Turbulence. Proc. Combust. Inst. 2009, 32, 1-25. [CrossRef]

61. Peters, N. Laminar Diffusion Flamelet Models in Non-Premixed Turbulent Combustion. Prog. Energy Combust. Sci. 1984, 10, 319-339. [CrossRef]

62. Combustion Research Group at UC San Diego. Available online: http://web.eng.ucsd.edu/mae/groups/ combustion/index.html (accessed on 4 February 2020).

63. Government of Mexico. Available online: https://www.gob.mx/cms/uploads/attachment/file/94616/gasLP.pdf (accessed on 4 February 2020).

64. ANSYS FLUENT 12.0 User's Guide - 26.2 Choosing the Spatial Discretization Scheme. Available online: https://www.afs.enea.it/project/neptunius/docs/fluent/html/ug/node778.htm (accessed on 9 April 2020).

65. ANSYS FLUENT 12.0 User's Guide - 26.2.1 First-Order Accuracy vs. Second-Order Accuracy. Available online: https://www.afs.enea.it/project/neptunius/docs/fluent/html/ug/node779.htm (accessed on 9 April 2020).

(C) 2020 by the authors. Licensee MDPI, Basel, Switzerland. This article is an open access article distributed under the terms and conditions of the Creative Commons Attribution (CC BY) license (http://creativecommons.org/licenses/by/4.0/). 